NUREG/CR-0829

PNL-3021

\title{
A Measurement Control Program for Nuclear Material Accounting
}

Prepared by R. J. Brouns, F. P. Roberts, J. A. Merrill, W. B. Brown

Battelle - Pacific Northwest Laboratory

Prepared for

U.S. Nuclear Regulatory

Commission 


\section{NOTICE}

This report was prepared as an account of work sponsored by an agency of the United States Government. Neither the United States Government nor any agency thereof, or any of their employees, makes any warranty, expressed or implied, or assumes any legai liability or responsibility for any third party's use. or the results of such use. of any information. apparatus product or process disclosed in this report. or represents that its use by such third party would not intronge privately owned rights.

Available from

GPO Sales Program

Division of Technical Information and Document Control

U. S. Nuclear Regulatory Commission Washington, D. C. 20555

Printed copy price:

and

National Technical Information Service Springfield, Virginia 22161 


\section{A Measurement Control Program for Nuclear Material Accounting}

Manuscript Completed: September 1979

Date Published: June 1980

Prepared by R. J. Brouns, F. P. Roberts, J. A Merrill, W. B. Brown*

Battelle-Pacific Northwest Laboratory

Richland. WA 99352

*Staff, U.S. Nuclear Regulatory Commission

Prepared for

Division of Siting. Health and Safeguards Standards

Office of Standards Development

U.S. Nuclear Regulatory Commission

Washington, D.C. 20555

NRC FIN No. B 20149 



\section{ABSTRACT}

A measurement control program for nuclear material accounting monitors and controls the quality of the measurements of special nuclear material that are involved in material balances. The quality is monitored by collecting data from which the current precision and accuracy of measurements can be evaluated. The quality is controlled by evaluations, reviews, and other administrative measures for control of selection or design of facilities, equipment and measurement methods and the training and qualification of personnel who perform SNM measurements. This report describes the most important elements of a program by which management can monitor and control measurement quality. 



\section{SUMMARY}

A measurement control program monitors the accuracy and precision of measurement processes and provides controls for selection and application of measurement methods to help ensure consistent and acceptable measurement quality. Licensees subject to the requirements of Section 70.58 of $10 \mathrm{CFR}^{(1)}$ must establish and maintain a measurement control program for special nuclear material (SNM) accounting measurements. Close control of SNM measurement quality is needed to ensure that a loss, theft or diversion of SNM will not be masked by either bias or excessive random error in the measurement data used in the periodic material balances that are performed to verify the adequacy of SNM control and accounting. This report describes the technical and administrative elements that we consider to be important in a measurement control program.

A measurement control program should provide for:

- utilization of existing data and collection of additional data for monitoring the quality of all SNM measurements

- measurement data evaluation and control through appropriate statistical procedures

- administrative control measures over the selection or design of facilities, equipment and measurement methods

- control over selection, training and qualification of personnel who perform SNM measurements

- periodic program audits.

The program should be described in a manual to help provide for clarity and uniform implementation.

The data generated for measurement control are obtained from measurement tests designed to evaluate error behavior. Random error standard deviations of the measurement processes are usually derived from data obtained by performing repeated independent measurements of typical process materials and 
iterns, and by analyzing duplicate samples. Because it is important for the standard deviation estimates to be representative of typical routine SNM accountability measurements, the repeated and/or duplicate measurements should be:

- made in the same manner as routine measurements, i.e., the same equipment, instruments, operators and procedures

- made in an independent manner to ensure that all sources of random error are just as probable in duplicate measurements as they are in isolated measurements

- distributed evenly over the period of time that the SNM accountability measurements are made.

Bias in measurement processes should normally be determined and controlled by calibrations and routine measurement of reference standards. Comparative measurements using a measurement method that is widely accepted as a standard or "reference" method having a known or independently verifiable accuracy is a supplementary bias evaluation procedure. In cases where neither suitable reference standards nor a reference method are available, designed experimental tests of the measurement process may be used to evaluate the bias due to potential sources of error. The accuracy of sampling is generally established in this manner.

The function of calibrations and bias tests are to obtain bias-free measurement data. Usually, bias is eliminated by calibration (within the limitations imposed by the random error of the measurement process). However, every measurement process should be continualiy tested for bias to monitor the validity of the calibration and determine bias correction factors if required. Weighing devices and analytical methods are commonly monitored by measuring working standards daily. The frequency of bias testing should be established on the basis of historical monitoring data, e.g., control charts showing how stable the calibration of the measurement system has been, and on the potential impact of an uncorrected measurement method bias on the inventory difference (ID) of the material balance of the facility. 
The working standards used for routine tests of bias should be similar in form and composition to the process samples for which the measurement process is used to help avoid sources of error stemming from composition differences. In addition, the measurements of standards should be made in the same manner (i.e., same equipment, instruments, locations and personnel) that unknowns are routinely measured. The working standards must be calibrated against reference standards whose values are traceable to the national measurement system.

The data collection functions of measurement control must be supported by an adequate statistical evaluation effort to provide experimental designs, measurement control data analyses, hypothesis tests, and determination of limits for control charts. In addition, the organization of the nuclear facility should be structured to facilitate program effectiveness. The administrator of measurement control must have sufficient authority to carry out the program functions without constraints due to conflicting goals. A program plan is needed to describe the policies, organization, duties of personnel, instructions and procedures, and data collection plan. The program should also provide for:

- reviews and formal approval control of designs, specifications and installations of measurement and sampling equipment and other equipment

- review and approval controls on the selection of measurement methods, reference standards and calibration procedures

- control of selection, training and qualifying personnel who perform SNM measurements and related tasks, such as sampling and calibrations.

To ensure continued adherence by all personne? to the established measurement control program policies and procedures, a periodic audit should be performed for program management. The auditor should be a knowledgeable and competent person who has no role in the planning and operation of the program so he can make an independent assessment of the adequacy of the design as we1? as its implementation. 


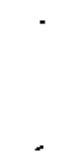

• 


\section{CONTENTS}

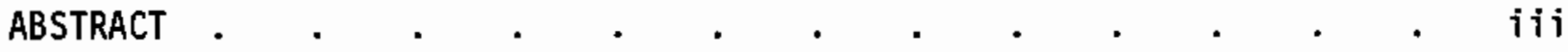

SUMMARY .

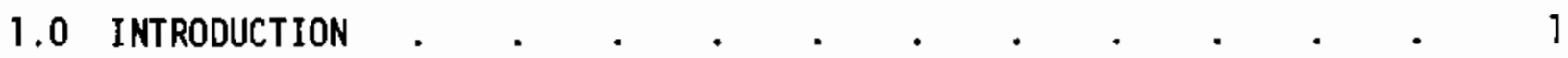

2.0 STATISTICAL CONSIDERATIONS AND OUTLINE OF A MEASUREMENT CONTROL

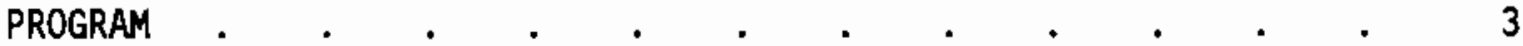

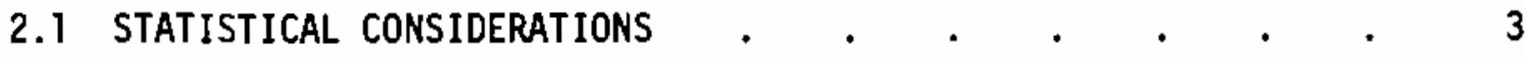

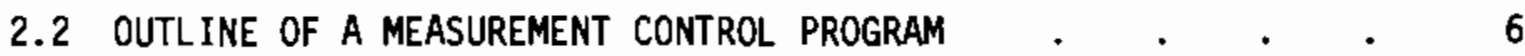

3.0 DETERMINING AND CONTROLLING MEASUREMENT ERROR $\quad . \quad$. $\quad . \quad$. 9

3.1 MEASUREMENT OF BULK LIQUID VOLUMES . . . . . . . . . 10

3.1.1 Tank Calibrations . . . . . . . . . . 10

3.1.2 Random Errors in Volume Measurements . . . . 13

3.1.3 Control of Volume Measurement Quality . . . . 14

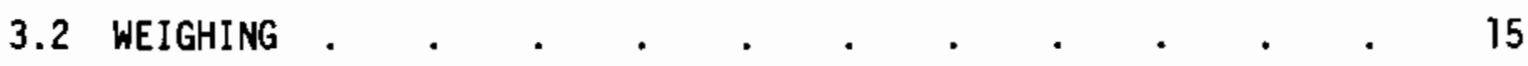

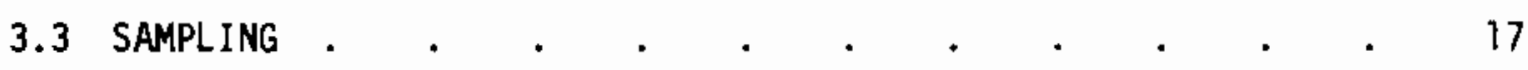

3.4 CHEMICAL ASSAY . . . . . . . . . . . . . . . . 22

3.5 ISOTOPIC ANALYSIS OF NUCLEAR MATERIAL $\quad . \quad$. $\quad . \quad$ • $\quad 25$

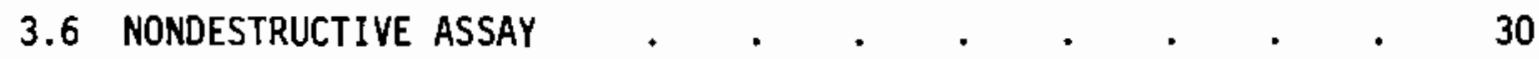

3.7 CALIBRATIONS AND STANDARDIZATIONS . . . . . . . . 34

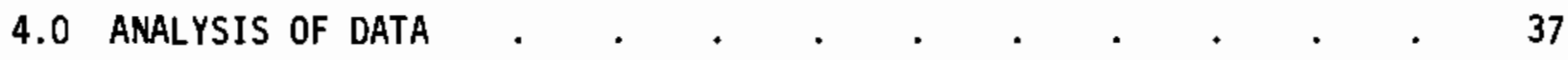

4.1 ESTIMATING BIAS . . . . . . . . . . . . . . . 37

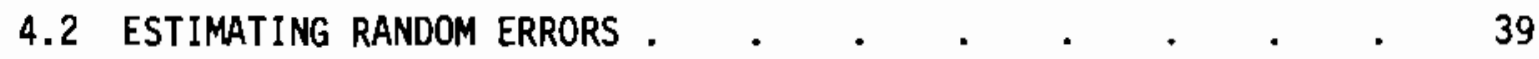

4.3 COMBINING ERRORS AND CALCULATING LEID . . . . . . . 40

4.4 PLANNING MEASUREMENT CONTROL DATA COLLECTION . . . . . 40

4.5 STATISTICAL DESIGN OF EXPERIMENTS $\quad . \quad$. $\quad . \quad$. $\quad . \quad$. 40 
4.6 NUMBER OF DEGREES OF FREEDOM REQUIRED $\quad . \quad$. $\quad . \quad$. 41

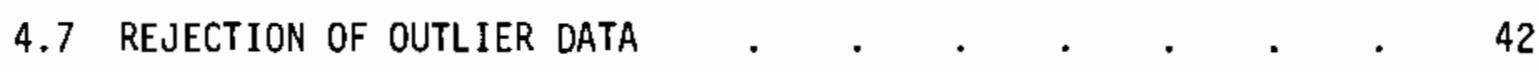

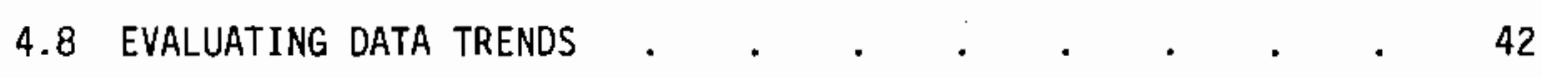

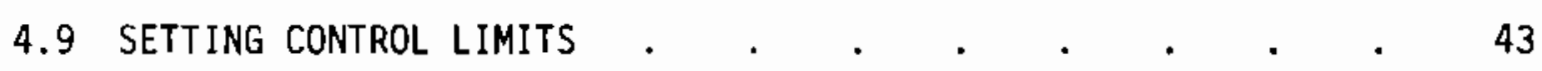

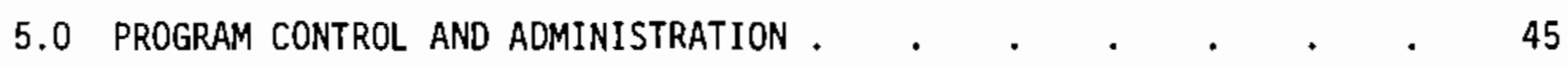

5.1 ADMINISTRATION OF A MEASUREMENT CONTROL PROGRAM . . . 45

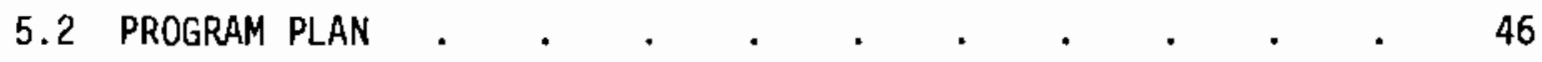

5.3 REVIEW OF DESIGNS, INSTALLATIONS, AND TESTS OF FACILITIES AND

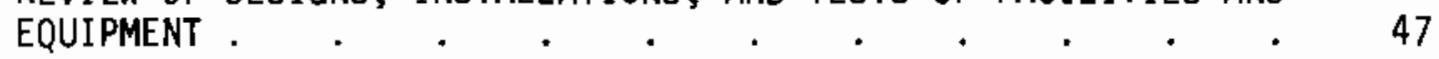

5.4 REVIEW OF MEASUREMENT METHODS . . . . . . . . . . . 49

5.5 TRAINING AND QUALIFYING PERSONNEL $\quad . \quad . \quad . \quad . \quad . \quad . \quad 50$

5.6 RECORDS CONTROL $\quad . \quad$. $\quad . \quad . \quad . \quad . \quad . \quad . \quad . \quad . \quad . \quad 51$

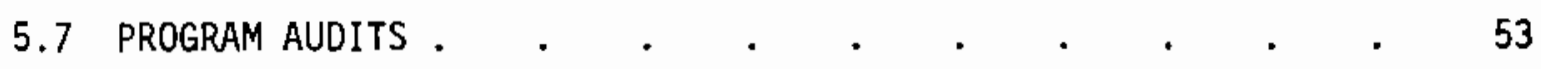

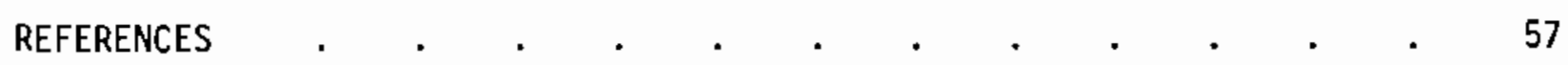




\subsection{INTRODUCTION}

This report describes the technical and administrative elements that are considered to be important in a measurement control program for special nuclear material accounting. The report was prepared by Pacific Northwest Laboratory (PNL) $^{(a)}$ for the Safeguards Standards Branch of the Office of Standards Development, U.S. Nuclear Regulatory Commission.

Measurement control has long been recognized as an essential part of any measurement program. Analytical chemistry and physical measurement laboratories commonly use formalized procedures to evaluate and control measurement errors. In many cases the procedures are no more than periodic measurements of a physical standard or reference material, and periodic replicate measurements to test the state of control of the measurement processes. More sophisticated programs are often used today and in the case of special nuclear materials accounting, measurement control is important because of the value of the materials and the need for assurance that no material has been stolen. The Code of Federal Regulations prescribes that any licensee who is subject to the requirements of Part 70.58 of $10 \mathrm{CFR}^{(1)}$ must establish and maintain a measurement control program for special nuclear material control and accounting measurements. The requirements of the program are specified in Part 70.57.

Physical and chemical measurements are the basic input to the material accounting systems used by industry and government to verify that nuclear material has not been lost or diverted. The effectiveness of the material balance accounting system hinges directly on the accuracy and precision of the measurements used to form the material balances.

Measurement control programs utilize data obtained from the measurement processes to monitor and evaluate measurement performance. The sources of the data are calibrations, replicate measurements, comparative measurements, and other techniques for evaluating the state of statistical control of the

(a)PNL is operated by Battelle Memorial Institute. 
measurements. Evaluation also includes calculation of biases and random error standard deviations, deriving calibration curves, testing for outliers, setting control limits, and monitoring error trends by both control charting and statistical hypothesis testing. Although monitoring and evaluating the measurement processes are the major functions of the program, other essential elements include controlling the selection of measurement methods, training and qualifying measurement personnel, and reviewing the designs and installation of equipment and instruments that affect measurement quality. In addition, effective administration of the measurement control program requires an organization with adequate skills, dedication and authority to carry out the prescribed functions. 


\subsection{STATISTICAL CONSIDERATIONS AND OUTLINE OF. A MEASUREMENT CONTROL PROGRAM}

\subsection{STAT IST ICAL CONSIDERATIONS}

When nuclear material is processed in bulk (unpackaged) forms, mass balance accounting is necessary, which involves measurements of weights or volumes and compositions rather than item accounting. In mass balance accounting, the accounting records and measured inventories may differ because of the cumulative effect of errors inherent in measuring the quantities of material received, shipped, and on inventory. Other causes of a material balance difference include unrecorded losses, thefts, diversions, and record keeping or measurement mistakes. The difference is identified in the material balance equation as inventory difference (ID):

$$
B I+A-E I-R=I 0^{(a)}
$$

where

$$
\begin{aligned}
B I & =\text { beginning (physical) inventory } \\
E I & =\text { ending (physical) inventory } \\
A & =\text { additions to beginning inventory } \\
R & =\text { removals from inventory } \\
I D & =\text { inventory difference }
\end{aligned}
$$

Because of the measurement errors, an ID cannot be interpreted simply as an actual loss (or gain) of material. The problem, then, in testing for loss of material is to determine by statistical methods if the observed ID is significantly different from zero, after making allowances for the measurement uncertainties in the calculation of the material mass balance. This determination can be made if the magnitudes of all the measurement uncertainties affecting ID are known.

(a) In Part 70.51(a) of $10 \mathrm{CFR}$, MUF is used rather than ID. The newer term (ID) will be used in this report (see Reference 2). 
A knowledge of the potential size of the measurement process errors provides a quantitative basis for an alarm criterion for initiating an investigation. The currently designated alarm criterion is based on the limit of error of the inventory difference (LEID). ${ }^{(3)(a)}$ To the extent that LEID can be kept smal1, the material balance accounting system will be sensitive to small losses or thefts. For LEID to serve as an effective tool in material control, it is important that it be as small as practical and that it be based on the actual current statistical estimates of the measurement errors. Consequently, all sources of error that affect the material balance should be taken into account and the error data handled correctly, in a statistical sense, in estimating LEID. Current and valid measurement error information is ensured if a measurement control program is maintained for monitoring the errors and controlling the activities that affect the error of all SNM measurements.

To establish a measurement control program, the measurement systems must be controllable, i.e., the probability of the measurement data falling within specified limits may be predicted. Once this condition is fulfilled a data collection and analysis system can be established for identifying and monitoring the sources of measurement variation, and performance limits can be set for the measurement systems. Control charts are commonly used to indicate whether the measurement process is in statistical control and to provide a bas is for action to correct unacceptable performance. A measurement process is in statistical control when sets of measurements from the process behave as random samples from a stable probability distribution.

Measurement error control, like any other control system, involves the processes of: 1) detection of change from expected performance, 2) feedback of information about the change to a control unit, 3) investigation of the change to determine the cause, 4) initiation of corrective action, and 5) follow-up to assure that the corrective action is timely and adequate. The primary parameters controlled by a measurement control program are the accuracy and precision of measurements.

(a) In 10 CFR7D, LEMUF is used rather than LEID. The newer term LEID will be used in this report. 
In materials accounting measurement systems, the random and systematic components of error must be distinguishable and separable. This is necessary since these two types of error are treated differently in summing and propagating errors to calculate LEID. ${ }^{(4,5)}$ Although the concepts of random and systematic measurement errors are generally accepted, there is considerable variation in terminology and in the statistical handling of the components of error.

For the purposes of this report, the following terminology and concepts are used. An error that behaves as if it were randomly chosen from a population of similar errors having a given frequency function is called a random error. Such errors affect the reproducibility or precision of a measurement without affecting the expected or limiting mean value. Independent replication of measurements reduces the effect of random errors on mean values. A systematic error or bias, on the other hand, affects all observations in a given data set in the same direction and by the same amount. Bias and systematic error are often considered as synonymous. Although bias is defined in Part 70.57(a)(6) of 10 CFR as "a systematic error whose value has been determined and whose effect can be corrected for, "the term bias will be used in this report in the broader sense of a constant error (an offset from the "true value" (a) $)$ for a particular set of data regardless of whether its value has been determined. $(b)$

The estimation of bias, whether by measurement of reference standards or by other techniques, is subject to the uncertainties contributed by random measurement errors and other sources such as the uncertainty in the assigned value of the reference standard. Therefore, the standard deviation of the bias estimate affects the standard deviation of a bias-corrected measurement. Measurement results are not always bias-corrected, presumably because the estimated value of the bias of the measurement process is not statistically significant (therefore assumed to be zero). In this case, the standard

(a)Though we use the traditional expression, true value, some writers prefer target value, sought-after value, or accepted value. $(6)$

(b)A general definition of bias is the deviation of the expected value of a random variable from its corresponding correct value. 
deviation of the calibration or the standard deviation of the bias estimate whichever is applicable, affects the uncertainty of the measurement data and should be included appropriately when estimating the standard deviation of a measurement result and when combining error estimates to obtain the standard deviation of an ID value. (a)

Random error and bias effects in material balance data evaluation may also be discussed through the use of statistical error modeling. The subject is treated in this manner in several publications by Jaech $(4,7,8)$ and other views on the issue have been given by Moore ${ }^{(9)}$ and Suda. (10)

\subsection{OUTL INE OF A MEASUREMENT CONTROL PROGRAM}

The principal measurement operations involved in nuciear materials accounting systems are weight and volume measurements, sampling, laboratory analyses, and nondestructive assay. The uncertainties in each of these operations contribute to the uncertainty of the material balance through the measurements of inputs (receipts), outputs (products, scrap, and measured discards), and physical inventories. The sources of data for estimating the errors associated with these operations are, primarily, analyses of standards, calibrations, special measurement tests, mixing and sampling tests, replicate measurements of bulk material quantities, replicate analyses of samples, and analyses of replicate samples. Table 1 outlines a typical program for acquiring the source data for error determinations.

The data obtained from an error monitoring program should be analyzed by statistical methods such as the analysis of variance to identify significant sources of random error and bias and to estimate the variance components. The estimates of variance components are used to set control limits for control charts and to set data rejection criterion (outlier tests). To ensure that the data obtained can be anaiyzed effectively, statistical experimental design methods need to be incorporated when designing sampling plans or special methods tests.

(a) Jaech incorporates the uncertainty associated with estimates of systematic error in the term systematic error standard deviation (see Chapter 3 of Reference 4). 


\section{TABLE 1. Typical Data Acquisition Plan for a Measurement Control Program}

\section{_. Measurement}

Liquid valume Measurement

Weighing

Sampiing

\section{Measurement Control Procedure}

Calibration of system and periodic recheck of calibration.

Check of specific gravity measurement devices by periodic measurement of pracess samples in the analytical

ratory

Regular inspection or testing of liquid level gâuges.

Independent replication of volume measurements of process materials at a
frequency consistent with sound statis. tical practices.

Scale ${ }^{(a)}$ calibrations and frequent operator checks with standard weights. Periodic inspection, maintenance, and recalibration of ali scales.

Independent replication of weighings of process moterial st at a frequency consis

Mixing and sampling tests.

Periodic replication of sampling by independent procedures.

Analys is of independent replicate samples at a frequency consistent with sound statistical practices.

Laboratory Analys is

Calibration or standardization of instruments and reagents.

Analys is of standard samples that simulate process samples.

Analys is of independent replicate process samples.

Replicate analyses of samples.

Calibration of instruments.

Frequent operator check of instruments using working standards.

Independent replicate measurements of items at a frequency cons/stent with

Periodic comparative analysis of items
by an accepted reference andiytical by an accep
method.
To ensure accuracy and to estimate the standard deviation of the calibration.

To ensure proper functioning of the instruments, to ensure accuracy, and to estimate bias.

To ensure proper functioning of the instruments.

To estimate the random error standard deviation of volume measurements.

To ensure accuracy and to estimate the standard deviation of the calibration.

To ensure continued accuracy.

To estimate the random error standard deviation for wighing process materials.

To establish operating procedures for bias-free sampling.

To test for sampling bias.

To estimste the combined random error standard deviation of sampling and analysis (also see Laboratory Analysis).

To ensure accuracy and to estimate the standard deviation of the calibration.

To estimute bias.

To estimate the combined random error standard deviation of sampling and analysis.

To estimate the randam error standard deviation of analys is.

To ensure accuracy and to estimate the standard deviation of the calibration.

To ensure that the instruments are functioning properly and are within acturacy control iimits.

To estimate the random error standard deviation of anaiysis.

To estimate bias.

(a)Scales will be used to refer to all weighing devices. 
Neither the variances or biases of sampling and measurements are likely to be constant over long periods of time. Therefore, it should not be assumed that data collected in the past are applicable to current measurements. Frequent monitoring distributed uniformly over the time when the measurements are applied tends to ensure that the measurement data will reflect the current conditions. In addition, the dynamic character of the measurement system used for material control requires that the measurement data collection plan be flexible. Conditions in the facility such as material composition, equipment used for sampling or measurements, personnel, and procedures can vary with time, and may necessitate revision of the data collection plan for the measurement control program. A continuous evaluation of data requirements can assure that current needs are being met and that no unneeded data are being collected.

Since many facilities have unique characteristics that can affect the kind and/or amount of data needed to evaluate the measurement errors, only a generic plan for acquiring measurement control data can be described. The sources of variation in measurements, the estimates of the standard deviations due to these sources, and their potential impact on LEID need to be considered in establishing the measurement control plan.

Besides calibrations and error monitoring, other activities in a facility can significantly affect measurement quality. The measurement control program should include appropriate administrative measures to control these activities. The principal administrative measures are:

- control of measurement method selections

- control of training and qualifications of personnel who perform measurement functions

- review of designs of facilities and measurement systems

- review of test procedures and test results for measurement systems prior to use

- maintenance of an effective information system

- periodic reviews and audits of the measurement control program. 


\subsection{DETERMINING AND CONTROLLING MEASUREMENT ERROR}

A formal plan is needed for the collection of measurement control data for calculating random error standard deviations and estimating biases and the standard deviations of the bias estimates for all the measurement systems used in SNM accounting. The basic requirements of the data acquisition plan are that all sources of measurement error that affect the limit of error of an inventory difference (LEID) are accounted for and that the random error and bias are separable in the data. The plan also provides for acquiring data for setting control limits used for routine monitoring of measurement system performance and for adjusting measurement results for bias. In the remainder of this section some general guidelines for measurement control are presented, followed by specific guidelines associated with particular measurement processes.

Sufficient measurement control data from each material balance period are needed to permit independent calculation of the random error standard deviation and bias of each measurement method for that period. The objective is to ensure that the standard deviation and bias estimates are representative of the current performance of the measurement process. A set of measurement control data collected during an earlier period may be pooled with the current data set if statistical tests indicate that the two distributions are not significantly different in their means or variances.

Generally the standard deviation for a measurement process should be based on at least 15 replicate measurements, but much more data are needed when individual sources of error, such as operator, instrument and sample effects are to be estimated. (There is further discussion related to this point in Sections 4.5 and 4.6.) The amount of data needed for estimating random error standard deviations, bias estimates and the standard deviation of bias estimates cannot be stated generally but should be determined for each measurement system using experimental design techniques. This topic is beyond the scope of this report and the reader should consult texts on the subjects, such as reference 11 . 
Replicate measurements used to estimate standard deviations should be made independently and include all routine procedural steps. For example, when duplicate samples are taken if a mixing procedure normally precedes the initial sampling, a short period of mixing should be repeated before the second sampling. The samples should be taken at different locations in the material. Also, if the first sample is a composite of subsamples from randomly chosen drums of a lot of material, the duplicate sample should be a similar composite from an independently selected set of randomly chosen drums. Similarly, duplicate bulk measurements and analyses should be independent and should follow routine procedures as closely as possible. It may be advisable to separate the two measurements in time or have them made by different persons.

Routine accuracy checks using appropriate reference standards should be frequent enough for each measurement method to independently verify its calibration or to calculate a bias correction factor. Generally, no less than two measurements of standards should be made each week for each material type and each measurement method, al though no general rule will be adequate for all cases. Some measurement methods should be checked daily, but equipment having very stable calibrations (perhaps scales and measurement tanks) may not need such frequent checks. The frequencies required should be determined from an analys is of historical information on calibration stability and the sensitivity of the material balances to biases in that particular measurement process and to the standard deviation of the calibration. Calibration of a measurement tank or in-process instrument that is not accessible for frequent recalibrations should be sufficiently thorough and precise that the standard deviation of the calibration meets applicable constraints on LEID.

\subsection{MEASUREMENT OF BULK LIQUID VOLUMES}

\subsubsection{Tank Calibrations}

Volume measurements are made in calibrated tanks equipped with instruments for determining the liquid level. From a calibration curve the liquid level reading is converted to a volume estimate. 
The calibration equation of a linear volume measurement tank is $h_{L}=\alpha+\beta V$ and the working equation for volume measurement is $V=\left(h_{L}-\alpha\right) / \beta$, where $V$ is the volume of liquid, $h_{L}$ is the liquid height in the tank, and $\alpha$ and $\beta$ are calibration constants, namely, the intercept and slope of the calibration curve, respectively. The liquid level, $h_{L}$, may be measured by any of several instrument systems. A conmon system used for remote tanks in highradiation zones is the pneumatic probe system in which the primary measurement is the differential pressure $(\Delta P)$ due to the liquid height. The $\Delta P$ measurement is made by a force balance sensor or a simple liquid filled manometer between air bubblers at two points in the tank one submerged near the bottom and the other above the maximum liquid level. The density of the liquid may be measured in a similar manner using two submerged probes with a fixed vertical separation. The density is needed to convert the $\triangle P$ value between the top and bottom of the tank to the liquid height. The mathematical function for liquid height is $h_{L}=h_{M} \rho_{M} / \rho_{L}$, where $h_{M}$ is the liquid height in the manometer and $\rho_{M}$ and $\rho_{L}$ the densities of the liquids in the manometer and the tank, respectively.

Although well-designed measurement tanks are not expected to change calibration over long periods, they should be checked periodically. In addition, they may need to be recalibrated to improve the calibration factors and reduce LEID. Minimum bias in the calibration of a measurement system is particularly important for mainstream flow measurements such as an input measurement of a chemical reprocessing plant or scrap recovery process.

Changes in the dimensions of a tank from relief of stress or physical distortion under load can affect its calibration. Other calibration changes can result from corrosion of the lower pressure sensing tube and other internal surfaces of the tank, or when internal components of the tank are replaced. The liquid capacity of the tank can also change due to buildup of sediment. This ordinarily affects only the heel volume (the residual contents of the tank not normally removable by pumping), which is part of the tank inventory but should not affect the volume of transfers. 
Bias evaluations and calibrations of volume measurement systems involve both the tank and instrument calibrations. For one common system, these would include the calibration constants of the calibration curve and the calibrations of the liquid height, density and temperature measuring instruments.

One recommended tank calibration procedure is described in an ANSI standard. (12) The calibration is performed by filling or emptying the tank in a series of increments of known volumes of liquid. As recommended in the ANSI standard, the calibration standard, which is either a weight prover or a volume prover, ${ }^{(a)}$ should be of such size that each increment of liquid added during a calibration pass is no more than one-sixteenth of the capacity of the tank.

At least two calibration passes should be made for a calibration, and more may be required to obtain an acceptably small standard deviation of the slope of the calibration curve. If the standard deviation of the slope is not small enough, additional calibration passes should be made to acquire more data. The standard deviations of the slope and intercept are calculated from the calibration data, as described in References 4 and 12 and in many statistical texts.

If the tank cannot be completely emptied and cleaned before each calibration pass, the residual volume or heel cannot be redetermined. In such a situation, one recourse is to accept the value obtained from the previous calibration of the tank. Any bias in the heel volume will be reflected in the intercept and will result in bias in the inventory of the tank contents but should not affect the accuracy of the slope nor of transfers to and from the tank.

Bias in volume measurements may arise from other sources besides tank calibration error or changes in calibration, as mentioned above. For instance, a buildup of sediment in a tank will change the effective volume of the heel and will contribute bias to inventory measurements. Thus, measurement tanks should be periodically checked for sediment and cleaned out if necessary.

(a) Calibrated volume provers are commercially available. A properly designed tank on a calibrated scale will serve as a weight prover. (12) 
Any of the instruments used in the measurements of liquid level, such as pressure and temperature sensors, can give biased results. Some possible causes of error are electrical disturbances, degradation or failure of instrument components, or uncompensated changes in ambient temperature. Liquid level values obtained using liquid filled manometers are affected by the densities of both the tank contents and the manometer fluid, as shown by the equation $h_{L}=h_{M} \rho_{M} / \rho_{L}$. Compensation for density variations with temperature can be made routinely, but because potential contamination, aging, and radiation damage can affect the density of the manometer fluid, the fluid should be replaced or its density remeasured periodically.

Residual volumes in process vessels that cannot be completely drained or pumped out and holdup of material in process equipment (columns, pipes, furnaces, etc.) usually must be measured for physical inventories. (13) The accuracy of these measurements is determined by calibrations and tests of material recovery. If the heel or holdup cannot be reliably measured in-situ, it may be cleaned out or flushed into a calibrated tank for inventory measurement.

\subsubsection{Random Errors in Volume Measurements}

The random errors of volume measurements are due primarily to the inherent nonreproducibility of the measurement instruments and to the variability introduced by operators reading liquid height and specific gravity instruments. Random errors may also be introduced by short-term fluctuations in ambient temperature that change the density of the manometer fluid used in pressure sensing devices and by incomplete mixing of tank contents, which can affect the specific gravity measurements. Lack of care and skill by operators can also be a source of volume measurement error. Some operators may make instrument adjustments or read instruments in a manner significantly different from others. Such reading differences do not necessarily cancel, even in measurement of volume transferred, which involves the difference between two liquid level readings, because these two readings may be made by different operators. Consequently, operator skill and adherence to approved procedures are important. 


\subsubsection{Control of Volume Measurement Quality}

The quality of volume measurements should be controlled by a program of recalibrations, monitoring measurement performance, and regularly scheduled testing and maintenance of the volume measurement instrumentation. The random error variance of volume measurements should be monitored by repeating measurements frequently. The duplicate measurements should be independent and each should include all normal measurement steps, such as mixing the tank's contents, manometer readings, temperature readings, and specific gravity determinations, and by using different operators at different times for the second measurement.

Measurement tanks should be calibrated periodically to maintain control over bias. Since the tank must be empty and clean for a calibration, and the time required to perform a calibration may be days, calibrations are usually only practical during plant shutdown periods. Therefore, volume measurements should be periodically checked for bias by other techniques in the period between complete calibrations. Some techniques are:

- transferring known volumes of liquid from a "volume prover" or a weigh tank to the measurement tank

- making comparisons of in-plant tank volume measurements of liquid transferred from one calibrated tank to another

- measuring the dilution factor for a constituent of the tank solution (e.g., by use of the tracer addition method).

These techniques will have a somewhat limited sensitivity for detecting bias because of the large variability of the measurements, but they can serve as a check for a serious error in calibration.

Another part of measurement control is the periodic check of the calibration of instruments associated with volume measurement. For example, where the differential pressure method of liquid level measurement is used, the manometer fluid density and the calibrations of manometers, thermometers and density instruments should be checked periodically. Differential pressure 
instruments can be checked by parallel measurements with portable precision manometers. Density instruments can be monitored by comparison with analytical laboratory measurements. In addition, the instruments should be inspected and tested on a routine majntenance schedule and should be adjusted or repaired when necessary. Inspections and tests should be made at least as often as the beginning of each material balance period. Control charts for bias and random error should be maintained on each measurement instrument.

The calibration standard deviation for volume measurement is derived primarily from the tank and instrument calibration data. It is a function of the uncertainties associated with: 1) the calibrations of the tank and the liquid level measuring and specific gravity measuring instruments, and 2) the temperature correction factors for the manometers. The statistical procedures for deriving the standard deviations of volume measurement system calibrations from the calibration data have been described elsewhere. $(12,14,15)$

\subsection{WEIGHING}

Weighing of nuclear material usually involves the measurement of gross and tare weights. The errors of both contribute to the error associated with the net weight. The common sources of error in weighings are the random variations due to the inherent limits of reproducibility of the weighing devices (hereafter referred to as "scales"), variations between operators in reading, rounding and recording data, and environmental effects such as variations due to temperature, humidity fluctuations, and vibration. These errors are usually random in nature. Bias can occur if the environmental conditions that prevail during routine use are different from those during calibration.

Weighing errors can be controlled by a program of periodic calibrations, routine monitoring of scale operating performance, and regular maintenance of the standard weights and scales. Regular inspections and maintenance are important because the sensitivity and reproducibility of most scales are affected adversely by accumulation of dust, corrosion, and mechanical wear or damage. 
Scales in routine use should be tested daily with calibrated check weights to ensure continued accuracy. The tests should be made in the same way that process material is weighed. If scale readings for the check weights fall outside preestablished control limits, the scale should be taken out of service until it has been repaired and recalibrated. Regardless of the day-to-day performance of a scale, recalibration should be done periodically to ensure that the scale is still accurate over its entire range and to verify the linearity and reproducibility of the scale. Recommended procedures for calibrating test weights and weighing devices are available in References 76 and 17.

The standard deviation of weight measurements due to random error can be estimated from replicate weighings of process materials. The standard deviation should be monitored for each scale by reweighing process items at different times by different operators so that all potential sources of error are inciuded.

The random error standard deviation of weight measurements could also be estimated from replicate weighings of standards. However, because operators tend to take more care with weighings of standards and test weights, data from such weighings are likely to indicate better precision than that from weighings of process materials. The latter data are more likely to be representative of routine weighing performance. Operators should be trained to read scales and to interpolate and round off data in a consistent and uniform way to reduce random error standard deviation and to avoid systematic differences between operators.

Cleaning, inspection, and maintenance of the scales at regular intervals, and particularly just prior to the recalibrations, is necessary to control weighing errors. The frequencies of maintenance and of recalibration of each scale should be based on the performance history of the scale as indicated by the pattern of the daily check data. 


\subsection{SAMPLING}

Sampling materials is the process of selecting a subset or part of the entire population of material from a tank or container to represent a batch, lot, shipment, or inventory stratum in analyses or tests. The process of sampling and preparing samples for analyses may involve several other steps. Examples are compositing, splitting (subdividing), drying, blending, particlesize reduction (grinding, milling or crushing), and screening. Particle-size reduction, screening and blending may either precede or follow splitting.

Sampling procedures are, to a great extent, process dependent, and specific procedures often are applicable to only a particular facility. Differences in equipment and processes often preclude simple transfer of a successful sampling procedure from one facility to another. An understanding of the properties of a material and, particularly its degree of homogeneity, is necessary before a good sampling procedure can be established. The most important consideration is that the samples be representative, in the statistical sense, of the bulk material sampled. Important sources of guidance in sampling practices are found in References 18 through 24.

Any of the many steps that occur between selecting the sample items, units or increments and making the final'measurements can contribute to sampling error. The potential sources of error are:

- heterogeneity of the material sampled

- changes in composition of samples during the sample increment selections, during the compositing, splitting, and preparing of analytical samples, or while awaiting analysis

- contamination or dilution of samples in sampling equipment such as by residual liquid in sampling lines from previous samplings or from purging with water or steam

- contamination during sample reduction process from wearing of grinding equipment surfaces 
- in the case of liquids, the presence of suspended solids or multiple liquid phases

- in the case of powders, use of a sample increment size that is too small relative to the particle size distribution of the material (See References $20,23,24$.)

- segregation among powder fractions during sampling, mixing, splitting, and subsampling because of particle size or density differences (See References 22, 23.)

- improper design or malfunctioning of sampling and mixing equipment

- fajlure of operators to follow prescribed procedures.

Variability of material composition within the sampling unit (i.e., item, batch or lot) generally is a source of random sampling error. If the composition varies in a nonrandom fashion, special care must be exercised to obtain random samples from the material to avoid sampling bias.

Homogeneity(a) within the sampling unit is usually not difficult to achieve with single-phase liquids, but difficulties can arise with solids, highly viscous liquids, and multiphase systems. Very heterogeneous materials such as cladding hulls, dirty scrap, dry wastes and multiphase process materials present the most difficult sampling problems. Obtaining representative samples of these and testing their validity may be impractical. Alternative measurement methods using nondestructive assay (NDA) can eliminate the need for sampling. If NDA cannot be used, consideration should be given to additional processing of the materials to convert them to a form more amenable to sampling. Incineration, pulverization and blending, total dissolution and phase separation are a few of the possible approaches.

Some powder mixtures have a tendency to segregate by particle size in handling. Blending such powders by the comono rolling, tumbling, or stirring methods sometimes does not produce a random mixture. This problem and possible solutions are discussed in References 22-25.

(a) The term homogeneity is used in a macroscopic sense. Some authors prefer the term "random mixture." 
Samples should be taken by random selection procedures to obtain samples that are representative of the population being sampled. Probability sampling requires that: 1) every portion of the population have a finite chance of selection, 2) the probabilities of selection be known, and 3) the measured values be weighted in inverse proportion to the probabilities of selection, either in sample compositing or in the computations. (18) Grab or dip sampling is acceptable only if the material sampled has been shown to be homogeneous. It is sometimes necessary to sample heterogeneous materials. In such situations, stratified procedures may be a help if stratification of the population is possible. When it is not possible to stratify the population, some form of simple random sampling is necessary to guard against sampling bias. Random error can be reduced by taking a number of subsamples and preparing a composite sample. The number of subsamples required for a desired precision can be calculated by statistical procedures (see Reference 20 ).

Sampling error can be controlled by continual monitoring and by establishing accurate sampling procedures. The performance of operators should also be monitored to ensure that the procedures are followed. Procedures that provide representative samples are usually developed by experimental testing. The primary goal of the testing is to develop a procedure that has no significant sampiing bias. When possible, a premixing procedure is established (also by experimental tests) that produces a homogeneous material. If the bias cannot be reduced to negligible levels, sufficient information about causes of error may be collected experimentally to derive a bias correction factor and the standard deviation associated with it.

Mixing and sampling tests for developing sampling procedures usually consist of: 1) analyzing sets of replicate samples after each of a series of mixing operations, and 2) comparing the standard deviations of the sets of samples calculated from the replicate data. Similarly, various sampling techniques are compared by analysis of sets of samples taken by each technique.

Sampling procedures should be tested for bias periodically and the standard deviation derived from the test data, e.g., by statistical evaluation of the measurement variability for test samples (see examples by Jaech). Methods for estimating sampling bias by experimental testing are: 
1. Comparing the measurement data from samples taken by the method under test with data from samples taken by an independent sampling procedure known to be substantially unbiased. Possible "unbiased" sampling procedues are:

- random selection of many sample increments from the vessel or flowing stream which are composited and thoroughly mixed to form the final sample

- selection of several sample increments that make up a large fraction (say $10 \%$ or more) of the batch of material. These are composited and thoroughly mixed to form the final sample

- use of one of the above after an extensive effort at homogenizing the batch

- selection of samples with a spinning riffler, progressively subdividing an entire batch to a suitably sized sample. (See References 22 and 23.)

2. Determining the effect of variations in a mixing and sampling procedure on sample composition, including such effects as mixing time, mixing and sampling technique, time delay before analysis, and ambient conditions. A mixing and sampling procedure having a negligible bias is designed on the basis of the test results. In this case it is necessary to take steps to ensure that all potential sources of bias are tested and that the span of testing conditions is adequate. A selected condition that can be varied with no observable change in the measured composition indicates that there is no bias attributable to the condition being tested.

3. Testing the sampling equipment and process using known synthetic mixtures. This is commonly done in pilot plant studies to aid in the design of a sampling system and sampling procedures.

The random error of sampling also should be monitored to ensure that process changes have not affected the degree of homogeneity of the material and to obtain current information for estimating the sampling standard devia- 
tion. The monitoring may consist of analyzing duplicate samples and estimating the standard deviation by the method of paired differences. (4) This will give an estimate of the combined error of sampling and analysis. Therefore, the analytical component must be removed to obtain an estimate of the sampling error. If the random error of the analyses is not known from other sources, an appropriate combination of duplicate samples and duplicate analyses data will permit separation of these two error components by a nested analysis of variance.

To achieve a valid estimate of sampling error, all sources of error that may affect routine sampling need to be included when obtaining the duplicate samples. Also, the duplicate samples should be taken as independently as possible and by the same procedure, including all mixing and handling steps as discussed previously.

Monitoring should also be distributed throughout the material balance period. This has two advantages: 1) it provides continual verification of the state of statistical control of the sampling process, and 2) it allows random error standard deviation estimates to be matched with sets of process data for the same period.

In order to promote consistency in sample handling, control procedures such as the following may need to be instituted:

- use of appropriately tested sample containers and packaging

- adherence to specific sample retention and storage conditions

- prescribed actions in unusual circumstances, such as when breakage, leakage, and departures from scheduled analysis time occur

- complete and consistent labeling and data transmittal

- recording of sample transfers through the use of internal material transfer documents.

All samples should be examined before analysis for any indication of abnormality. Generaliy, samples that appear abnormal due to the presence of multiple liquid phases, precipitates, leakage, or spillage should be rejected. 


\subsection{CHEMICAL ASSAY}

Laboratory analysis of nuclear materials may involve many measurement steps and manipulations which have potential for introducing error into the measurement. Typical steps encountered in analytical procedures are drying, mixing, subsampling, weighing, dissolving, separating, purifying and assaying. Determining individual sources of analytical errors and controlling them is of ten more complex and demands greater effort than for bulk measurements and sampling.

A listing of the individual sources of random error and bias that are encountered in chemical analysis may include:

- instrument variability, both within the normal limits of reproducibility of the instruments and as caused by environmental factors, such as varying voltage or temperature and malfunctioning equipment

- variations in chemical reaction rates and stoichiometry

- variations in the response of electrodes, chemical indicators, or other elements

- operator variability in making critical measurements and reading titration endpoints

- contamination of equipment and reagents

- calibration or standardization errors

- changes in composition between sampling and analysis

- incomplete dissolution of samples

- the presence of interfering constituents in samples

- the presence of the polymeric form of plutonium in solution samples being analyzed for plutonium

- performance differences between operators and between instruments

- errors in subdividing (and subsampling) samples received for analysis

- errors in weighing analytical sample aliquots and measuring volumes of aliquots and reagents. 
The preceding list is generic and probably incomplete. Many of the sources of error and their effects for specific methods are known from studies done during the development of the method and in adapting the method for specific applications. For measurement control it is usually sufficient to monitor the overall effects of all sources of error on the measurement results without attempting to distinguish between the sources. However, individual sources of error must be known when it is necessary to diagnose and correct loss of control situations.

The accuracy and precision of analyses can be monitored and controlled by calibrations, standardizations, method testing and independent replicate measurements. These would involve analyses of reference standards, (a) duplicate analyses of samples or items, method tests for the sources and magnitude of potential biases in the analyses, and comparative analyses of process materials by independent methods.

The analysis of reference standards should be distributed throughout the time that the analytical method is being applied to ensure that accuracy is continuousiy being monitored. The frequency for the measurement of standards needs to be sufficient to obtain a precise estimate of bias and its standard deviation each material balance period. In general, a bias test should consist of several independent measurements of a standard or standards; and the standard deviation of the mean of the results should be substantially less than the standard deviation of a typical single process sample measurement. This may require 15 or more measurements during the material balance period.

Standards used for monitoring analytical accuracy should closely simulate process samples in form and composition so that the analytical results are not affected by differences in composition between standards and the process samples. In addition, efforts should be made to perform analyses of standards and routine samples in an identical manner, including the preparation steps such as mixing, subsampling, weighing the analytical sample, dissolving and aliquoting.

(a) The subject of reference standards and their preparation or acquisition is discussed in Section 3.7. 
When it is not possible to duplicate compositions or material types in standards, an analytical procedure may be adopted that is highly specific and is not affected by the procedural or sample variations. The effects of differences between the standards and the routine samples can sometimes be determined by special studies. In these studies the effects of all potential sample constituents on the analytical results should be studied and one of the following courses taken: 1) pretreatments should be used to remove interfering constituents, or 2) the approximate concentrations of interfering constituents in each sample should be determined and appropriate corrections made. The measurement performance can also be monitored by comparative analyses using other assay methods and by interlaboratory sample exchanges and round-robin tests with standards.

The random error standard deviation of an analysis method is determined by evaluation of data from independent replicate analyses of samples. The usual procedure is to perform duplicate analyses routinely on some fraction of the samples received. These duplicate analyses should be made independently, including replication of all normal procedural steps (see Section 3.0). A common alternative is to perform single analyses of duplicate samples. In this case the standard deviation estimated from the replicate data includes both sampling and analytical error. Knowing the combined error is usually sufficient but when a knowledge of the individual sampling and analytical variances is needed, such as for method evaluation, a separation of error components can be made by analys is of variance methods as described in most statistical texts $(4,26,27)$ (also see Section 3.3 ). Evaluation of the contributions of individual sources of error, such as instrumental or day-to-day effects also requires an analysis of variance.

The data obtained from analyses of reference and working standards are sometimes used to calculate the random error variance of the method. However, these results may indicate better precision than is actually obtained from process samples because the standards data may not include the effects of composition variations, and because the analyses of standards may not be carried through all analytical steps (e.g., sample dissolution). Also analysts 
are usually more careful when running standards. Similarly, information on measurement error from development studies may not be applicable because it is usually generated by a few select persons on a single set of apparatus in a research laboratory and/or with synthetic samples and standards. Replicate results from process samples are a far better and preferred source of data because they are more representative of routine performance.

\subsection{ISOTOPIC ANALYSIS OF NUCLEAR MATERIAL}

The preferred method for the isotopic analysis of heavy elements is surface ionization mass spectrometry, although for some applications other methods are used. For example, gamma spectrometry is applicable to a limited number of isotopes and may be used where a rapid isotopic determination or a nondestructive technique is desired and a lower precision can be accepted. Alpha spectrometry is usually used for determining $238 \mathrm{Pu}$ in $\mathrm{Pu}$ at isotopic concentrations below $0.1 \%$. In addition, gas source mass spectrometry is usually used for the $235 \mathrm{U}$ enrichment determinations of $\mathrm{UF}_{6}$ feed material for fuel fabrication and for als enrichment measurements in uranium enrichment and enrichment feed preparation facilities. The gas source method is capable of higher precision than the surface ionization method but has a more limited applicability in isotopic analyses of nuclear material.

The discussion of errors in isotopic analysis will focus on the surface ionization method because of its much wider application in nuclear materials accounting measurements. An abundance of literature is available on isotopic analysis. Some suggested sources for the surface ionization method are References 28-31.

The isotopic analysis procedure for surface ionization spectrometry consists of: 1) chemical separation and purification of the desired element, e.g., uranium or plutonium, 2) mounting, drying and calcining a measured portion of a dilute solution of the purified element directly on a ribbon filament or pair of filaments to be inserted in the mass spectrometer ion source (rhenium metal is used for uranium and plutonium samples), and 
3) analyzing the metal ion spectra emitted from the source at high filament temperatures ("surface" ionization or "thermal" ionization) by energy/mass resolution in the mass spectrometer.

A variety of mass spectrometers are used, differing primarily in ion source and ion collector designs. Single and triple filament sources, Faraday trap and electron multiplier collectors and d.c. and pulse counting readouts are the common variations. Mass spectrometers are among the most complex analytical instruments used and considerable operational knowledge and skill are required to achieve the accuracy and precision needed for nuclear material balance accounting.

Mass spectrometer results usually require bias corrections. The main causes of bias are:

1. Source Discrimination Effect - This is primarily due to mass discrimination resulting from the preferential evaporation and ionization of the lighter isotopes of an element. Consequently, the observed isotopic ratios vary with time during an analysis, and calibration with reference standards under fixed operating conditions is required to determine the bias correction factor. Several things that can affect source discrimination are:

- Sample and ionizing filament temperatures

- sample quantity, i.e., filament loading

- chemical composition, acidity and purity of the element

- sample mounting and calcining procedure

- source and filament outgassing procedures

- analytical procedures, i.e., the heating pattern, schedule, temperatures and timing of the data collection.

2. Source Memory - Heavily contaminated sources may lead to cross contamination from previous samples and degraded resolution if the source and analyzer pressures get too high. 
3. Ion Optics Discrimination - The voltage effect of the ion beam causes some discrimination if voltage scanning is used.

4. Ion Collector Discrimination and Nonlinearities - Electron multiplier gain varies with ion mass and energy and with entrance position. Errors in response may be caused by noise due to alpha activity, stray charges and secondary electrons (for multiplier collectors), and counting loss errors (pulse counting with multiplier collectors). In addition, electronic nonlinearity in data logging systems is conmon. Other sources of error may be amplifier drift, non-ohmic responses of input resistors at large currents, and capacitance decay ( $R-C$ ) errors when switching from high current to low current signals.

To achieve adequate control of isotopic analysis errors, a carefully tested and standardized operating procedure for which the bias correction factors have been determined must be used. Frequent analys is of reference standards is necessary to provide continuously updated bias correction data. Not all of the sample and instrument parameters that influence the accuracy and precision of isotopic mass spectrometry are understood but considerable progress has been made in instrument designs and methodology to minimize random error and stabilize the accuracy. $(30,31)$

The random error in an isotopic analysis affects the precision i.e., the random error standard deviation, of an isotopic ratio. Random variability will be observed during a single analysis (one filament) and during multiple analyses of the same sample. A single analysis refers to the mean of the ratios obtained in running one sample filament and multiple analysis refers to several filaments prepared from the same sample. The standard deviation for a single analysis can be calculated from the ratios obtained from a single filament. The analysis usually proceeds as follows, using the $235 \mathrm{U} / 238 \mathrm{U}$ ratio as an example:

1. Focus on the ${ }^{235} \mathrm{U}$ peak and record the peak height or mean count rate for a fixed time period. 
2. Focus on the ${ }^{238} \mathrm{U}$ peak and, after a fixed time delay to allow the readout to stabilize ( $R-C$ decay time), record the peak height.

3. Refocus on the ${ }^{238} \mathrm{U}$ peak, allow the R-C decay time, and record the peak height.

4. Focus on the ${ }^{2} 35 \mathrm{U}$ peak, allow the $\mathrm{R}-\mathrm{C}$ decay time, and record the peak height.

5. Repeat the above "scan" pattern until 10 to 15 sets of data are obtained, each set of four peak heights being used to calculate one ratio. Ratios of ${ }^{236} \mathrm{U} /{ }^{235} \mathrm{U},{ }^{234} \mathrm{U} /{ }^{235} \mathrm{U}$, and ${ }^{23}{ }^{3} \mathrm{U} /{ }^{235} \mathrm{U}$ are measured in the same manner, interspersed with the ${ }^{235} \mathrm{U} /{ }^{238} \mathrm{U}$ scans so that all ratio measurements are distributed evenly throughout the entire period of the analysis. (a)

The standard deviation of the mean ${ }^{235} \mathrm{U} /{ }^{238} \mathrm{U}$ ratio calculated with the data collected in the analysis may be referred to as the within-filament standard deviation. The sources of observed ratio variability that may contribute to the random error of the mean are:

- Instrument variability, which is a function of the stabilities of the electronic components, source and detector noise and the effect of power supply influences such as voltage transients. (The instrument stability is usually high because a high degree of stability and self-regulation are built into the mass spectrometer electronics.)

- Isotopic fractionation that results in a change in the isotopic ratios over the period of the analysis. The rate of change is affected by the filament temperature, sample composition, quantity of sample, and the mounting and pretreatment procedure.

- The number of ratios measured, i.e., the statistical effect.

- The signal intensity; if the intensity is low, counting or peak height measurement uncertainty is an appreciable source of random error.

(a)The alternating "scanning" schedule is closely controlled to minimize the variability of the observed isotopic ratios caused by the isotopic fractionation occurring during the period of the analysis. 
- Chart recorder dead zone and linearity, when d.c. measurement of the detector signal is recorded graphically.

When more than one filament mount for a single sample is analyzed, additional sources of random errors that affect the results can be expected. A realistic measure of the random error standard deviation for an isotopic analys is should include between-filament as well as within-filament effects. To achieve a realistic estimate of the standard deviation for any isotopic analysis, the estimate should be based on replication data for samples and standards run by different operators using the various instruments in the laboratory and distributed over periods of weeks.

The probable sources of random error introduced when analyzing more than one filament from a sample are:

- day-to-day differences in instrument bias

- differences in sample filaments such as quantity, purity and composition of the element and loading and treatment procedures

- differences between operators in the manner in which they process the samples and collect the data

- differences in source and collector noise levels such as may be affected by pressure, cleanliness, memory and electronic effects.

The chemical procedures that precede the isotopic analysis may also affect the results because, as stated previously, sample purity, acidity and concentration of the element can affect filament preparation, emission and ionization efficiency, and spectrometer bias correction factors. Analytical error stemming from poor sample quality control can be avoided by an experienced mass spectrometer operator because the sampie mounting or ionization characteristics observed when the analysis is begun will be noticeably abnormal and the analys is can be rejected and another sample obtained. $(30)$

Errors in isotopic analysis are monitored by analyzing reference standards and replicate sample mountings, i.e., duplicate filaments, and estimating bias corrections and random error standard deviations from sets of monitoring data. 
Reference isotopic standards of uranium and plutonium are available from the National Bureau of Standards. Standards covering a wide range of isotopic ratios for ${ }^{235} \mathrm{U} /{ }^{238} \mathrm{U}$ are available but the ranges for the minor isotopes of uranium and for all plutonium isotopes are limited. Bias correction factors for most ratios outside the ranges of the standards are extrapolated from the available ratio data.

The random error standard deviation for an jsotopic analys is is calculated from measurements of duplicate filaments. However, it is useful to monitor and calculate the within-filament standard deviation, which is derived from the variations in the ratios for the various scans made with one sample filament. Comparisons of the standard deviations predicted from the count rate (assuming a Poisson distribution) and the within-filament variability with the between-filament standard deviation can serve as indicators of instrument (electronic) stability and "run" stability, respectively. The latter is probably a function of both the operator skill and the filament-sample quality.

\subsection{NONDESTRUCTIVE ASSAY}

Nondestructive assay (NDA) methods are subject to sources of error not common to other measurement methods. The methods are subject to errors due to extraneous radionuclides in the material, variations in the background radiation, and attenuation of the radiation being measured. Attenuation may be due to the SNM itself, the matrix, or the container. This is further

discussed in ANSI Standard N15.20 ${ }^{(32)}$ and in other publications. (33-36)

Sources of measurement error in NDA may be divided into three categories:

1. Measurement-to-Measurement Variations - The rep]icate measurements of the same item are affected by:

- randon variations in the counting rate between time periods

- variations in number of counts due to background

- instrument or electronic instabilities

- temperature and power fluctuations 
- nonuniform item positioning with respect to detectors and, if applicable, with respect to the excitation source (a geometry effect)

- nonuniform distribution of SNM or matrix material within a container (geometry and attenuation effects).

2. Item-to-Item Variations - Material variability can cause a difference in the response from items of the same SNM content because of differences in:

- SNM radionuclide composition (isotopic and daughter nuclides)

- distribution and density of SNM in containers

- amount, distribution and density of extraneous materials in the containers

- container geometry and composition.

3. Calibration Error - This type of error is due to uncertainty in the SNM content of the standards and uncertainty in the measured radiation response from the standards.

Bias can occur as a result of instrumental drift. Drift is contingent on the stability of the instrument and its sensitivity to changes in operating conditions. For example, bias occurs if an instrument that is temperaturesensitive is used at a temperature different from that at which it was calibrated.

Bias due to material variability (differences between the standard and the unknown items or item-to-item error) occurs because calibration standards that simulate every unknown in every respect usually cannot be prepared. For each NDA application, efforts are made to fabricate standards having the expected average characteristics of the unknowns. The error caused by material variability is minimal for very uniform materials such as fuel pins, fuel rods, pure metal or alloys, or pure oxides because the possible variations in SNM purity, matrix composition (including impurities), and item geometry are smal1. Less pure or less uniform.material, particularly scrap and waste, may vary in composition so widely from item to item that evaluating bias presents a more difficult problem. If the average composition is well known, standards 
can be prepared that represent that average. Over a long-term for a large number of items, the bias may approach zero but bias of a single item or a small number of items may be large and difficult to estimate. This problem and possible solutions are discussed in the following paragraphs.

It is sometimes possible to minimize sources of bias by:

- designing the instrument to be insensitive to the perturbing effect

- controlling the operating conditions or environment of the system

- segregating items to be assayed into categories having similar properties and calibrating for each category separately

- using a different NDA technique that is insensitive to the perturbing effect.

Obviously, eliminating the source of item-to-item bias is preferred but it may also be possible to correct for bias by calculating correction factors from: a) a knowledge of the effect of each interfering parameter on the NDA result, and b) a knowledge of the magnitude of the interfering parameters in each item (from other measurement data). The standard deviation of the bias correction for individual items can be estimated by either:

- calculating it from knowledge of the measurement errors for each interfering parameter in the unknown and the calibration standard deviations for the methods of calculating the corrections

- determining the sizes of the biases of NDA measurements by periodicaliy analyzing process items by an alternative method that has a much higher and known accuracy for the constituent of interest. The alternative method may consist of dissolving the entire item and performing chemical analyses, or it may be another NDA method known to be free of the source of error being evaluated.

Measurement-to-measurement error is simply the random error in nondestructive assay. The main source of measurement-to-measurement error is related to the statistical nature of the counting process, i.e., the nuclear decay process, the radiation detection process, and the electronic noise of the detection 
system. This error is most significant at low count rates. Methods for estimating its magnitude assuming a Poisson distribution are given in most nuclear chemistry texts. Measurement-to-measurement variations detected in replicate measurements of the same item include the effect of the counting process. If the replications are spaced in time or are made by different operators, they aiso measure time-dependent effects, such as instrument drift and between-operator effects.

In monitoring the measurement-to-measurement standard deviation, it is useful to verify that the observed NDA counts are Poisson distributed. This can be accomplished by comparing the Poisson-based estimate of the variance to a variance estimate computed from repeated observations. If the measurements are normally distributed, (a) the ratio $\mathrm{s}^{2} / \mathrm{s}_{\mathrm{p}}^{2}$ is distributed about unity as $x_{n-1}^{2} / f$, where $s^{2}$ is the sample variance based on $n$ observations, $s_{p}^{2}$ is the average Poisson-based variance, and $f$ is the number of degrees of freedom (usually $n-1$ ). A variance ratio exceeding the $x^{2}$ upper limit indicates sources of variance other than counting statistics. The principles and application of a chi-square $\left(x^{2}\right)$ test for this purpose are found in Section 9.34 of Reference 26 and in a recent Los Alamos Scientific Laboratory research progress report on NDA technology. (37)

NDA measurement accuracy and precision should be monitored both by frequent replicate measurement of process items, which evaluates random error performance, and by analys is of standards, method evaluations, and comparative analyses. The principal control measure should be the routine measurement of working standards with known SNM contents. The standards should have the following properties:

- The physical and chemical forms of the standard material and the process sample items should be the same.

- The distributions of interfering constituents and other material characteristics of typical sample items should be known and the standards should have these material characteristics at the mean values of these distributions.

(a) Ordinarily a usable NDA system has a sufficiently high counting rate that the Poisson distribution is well approximated by the normal distribution. 
Method evaluation using appropriately designed experiments can be used to determine the effect on the NDA response of variations in composition, form, and other parameters of items and the distribution of these parameters in typical items.

The results of such tests can be used to evaluate bias. Bias can also be monitored by periodic analysis of typical process items by an independent method such as a destructive chemical analysis or by other NDA methods if the other method is known to be free from bias.

\subsection{CALIBRATIONS AND STANDARDIZATIONS}

Calibration is the process of determining the numerical relationship between the observed output of a measurement system and the accepted value of reference standards for the characteristic being measured. The processes of calibration, standardization, recalibration and determination of bias corrections or bias correction factors are basically identical, al though initial calibrations and subsequent recalibrations may differ in such details as the range covered and the extent of testing for stability or drift-rate and linearity. For simplicity, the term "calibration" will be used to refer to any of these procedures.

Calibration procedures applicable to SNM measurements are found in the guides and standards of the American Society for Testing and Materials (ASTM), American National Standards Institute (ANSI), U.S. National Bureau of Standards (NBS), and the U.S. Nuclear Regulatory Commission, as well as the literature of manufacturers of measurement equipment. Procedures for calibrating scales, balances, and mass standards (weights) are described in References 16, 17, 38 and 39. Volume calibration procedures for tanks are available in References 12, 14, and 40, and additional volume calibration procedures are found in References 38 and 41 . Mass spectrometer calibration procedures are given in References 29, 31 and 42. Guidelines for cal ibrating NDA instruments are given in References $32,33,36$ and 43 . 
Reference standards of mass and volume used in industry can be purchased from commercial suppliers. These suppliers can provide certificates of traceability to national standards and the calibration tolerances (guidelines for establishing traceability are given in Regulatory Guide $5.58^{(44)}$ ). In addition, some suppliers and the NBS can provide recalibration services. $(38,39)$ Additional information on reference standards and their availability is found in References 29, 30, and 45-48.

Whenever possible, "working" standards (also called test, bench or check standards) should be used for day-to-day monitoring of measurement process and equipment accuracy. These standards should resemble both in composition and form the typical process materials or items to be measured and be calibrated against primary reference standards. Recommended preparation and calibration procedures for some common working standards for nuclear materials are given in References 47 and 48 .

Many of the forms and compositions of SNM-bearing materiat in nuclear facilities are difficult to represent by reference standards. Prominent examples are $\mathrm{UO}_{2}$ and $\mathrm{PuO}_{2}$, which can change composition in air due to moisture absorption and which cannot be ignited or dried to a fixed, reproducible composition. However, sintered, low surface area forms (pellets) of these materials are used successfully as working standards. In cases where a good simulation of process materials cannot be achieved in reference standards, alternative forms must be used and periodic tests made for bias by other techniques, as discussed in the preceding sections.

Control and protection of the reference standards in a facility call for specia1 consideration because a standard that may have been contaminated, damaged, or tampered with cannot be relied upon until it has been recalibrated. A common way to gain added assurance of the integrity of a standard is to cross-check it with other standards or with calibrated equipment to show internal consistency. In addition, external checks such as comparison of results with data obtained by other facilities (including shipper versus receiver weights and assays) are useful. Participation in industry-wide and government intercomparative measurement programs is another means of detecting possible measurement bias. 
The measurements of standards in calibrating a system are repeated enough times to reduce the uncertainties of the calibration parameters (mean calibration factor, bias correction factor, or slope and intercept of a linear calibration) to acceptable levels. Statistically, independent replication reduces the standard deviation of the mean inversely as the square root of the number of measurements $\left(\sigma_{\bar{x}}=\frac{\sigma_{x}}{\sqrt{n}}\right)$. However, after 10 to 15 replications have been made, the gain for each additional measurement is small, as can be demonstrated using the above formula for $\sigma_{\bar{x}}$.

It cannot be established for the general case just how small the uncertainty associated with calibrations should be, but it can be estimated for each specific application of a measurement system. This can be done by evaluating the effect of a potential calibration error on a typical ID (see Reference 49). The entire working range of a measurement system should be covered by its calibration. Although only two points are needed to define the slope of a linear calibration, a number of intermediate points are needed to verify its linearity. In general it is not good practice to extrapolate a calibration curve beyond the measured points on the curve.

In some cases the calibration has a single value. Examples are the volume of a volumetric flask or the titre of a chemical reagent. In other cases the values obtained by the system cluster about some nominal value, such as the assay of high purity uranium dioxide. Bias correction factors for such an assay procedure can be obtained from the measurement of a reference standard with a reference vatue of the uranium concentration near the value of the samples.

The frequencies at which working standards are checked against certified reference standards and at which certified standards are recertified would vary with the stability of the standard. Generally, the frequency is based on the results of stability tests performed by the user or on historical information. 


\subsection{ANALYSIS OF DATA}

Statistical methods play an important role in monitoring and controlling measurement errors and in testing of measurement data validity. The statistical approach is valuable in such activities as scheduling the collection of measurement control data, determining the amount of data needed, designing experiments for evaluating error sources, establishing criteria for rejecting data, and setting measurement control limits.

\subsection{ESTIMATING BIAS}

Two primary methods are used for estimating the bias of a measurement system: 1) comparisons using standards or 2) comparison with a measurement system accepted as a standard. If neither approach is possible, then a testing approach is sometimes used. (a)

In the first method, bias estimates and calibrations are derived by comparing measured values with the accepted values of standards. The standard deviation associated with a bias estimate or calibration provides a basis for bracketing the potential bias, i.e., the bias or calibration uncertainty, of the measurement results when the measurement process is used for unknowns. The standard deviation estimates should take into account such sources of error as the standard deviation in the reference values of the standards as well as the standard deviation of the calibration or bias measurement. A means of incorporating such errors into a single, simple "limit of error" term, however, is not agreed upon in the statistical community (see References 7-10). However, every effort should be made to estimate the effects of each source of error and to incorporate those that prove to be significant.

A calibration over an operating range (a regression) is typical of volumetric measurement tank and NDA instrument calibrations. In the simple case of a linear response relationship, which is common, the general operating curve would be $y=a+b x$, where $x$ and $y$ are variables and $a$ and $b$ are cali-

(a) The principal application for method testing as a means of bias estimation is in evaluations of sampling processes (see Section 3.3 as well as Reference 24). 
bration constants. In practice, $x$ may be an instrument reading and $y$ the corresponding estimate of SNM quantity. The estimated values for $a$ and $b$ along with their standard deviations are derived from the calibration data (the statistical regression, or least squares method, is comnoniy used). $(11,12,14,15,26,32)$ A description for the variance of the average $\hat{y}$ is given by:

$$
\operatorname{Var}(\hat{y})=\operatorname{Var}(\hat{a})+x^{2} \operatorname{Var}(\hat{b})+2 x \operatorname{Covar}(\hat{a}, \hat{b}) .
$$

The computational form of this variance of the average $\hat{y}$, for a given value of $x, x_{0}$, is:

$$
s_{\hat{y}}^{2}=s_{\varepsilon}^{2}\left[\frac{1}{n}+\frac{\left(x_{0}-\bar{x}\right)^{2}}{\Sigma\left(x_{i}-\bar{x}\right)^{2}}\right]
$$

where

$$
\begin{aligned}
n & =\text { number of observations } \\
s_{\varepsilon}^{2} & =\text { the residual mean square error from regression. }
\end{aligned}
$$

This variance, which is the result of the random errors in the calibration process, is a measure of the potential bias to the user of this particular calibration.

The second method for estimating bias is based on comparative independent measurements using an alternative method of well-established accuracy. The comparative measurement should be made by a method differing in principle from the routine method so that the two are unlikely to have the same sources of error or interference. Comparative measurement is commonly used for monitoring chemical analyses by:

- analysis in-house by an alternative method

- analysis in another laboratory (sample interchange) (a)

- using as a working standard a batch of typical process material that has been well-characterized by multiple analyses by various methods or at various laboratories. (a)

\footnotetext{
(a) If another laboratory is utilized in estimating bias, a program of audit consistent with section 5.7 must be completed at that laboratory before the measurement data is accepted and used.
} 
The standard deviation of the bias estimate may be estimated for these cases by statistical analysis of the paired comparison data. For the first two approaches care must be taken to incorporate the uncertainty of the measurements by the alternative method or by the other laboratory.

\subsection{ESTIMATING RANDOM ERRORS}

The random error variance of a measurement is estimated from replicate measurement data using the formula

$$
s^{2}=\frac{\sum_{i=1}^{n}\left(x_{i}-\bar{x}\right)^{2}}{n-1}
$$

for $n$ measurements, $x_{i}$, of one sample or item, or using

$$
s^{2}=\frac{\sum d_{i}^{2}-\left(\sum d_{i}\right)^{2} / n}{2(n-1)}
$$

for $n$ sets of duplicate values, where $d_{i}=x_{1} i-x_{2} i$ and $s^{2}$ is the variance estimate. For the case where the expected value of the differences is zero, this second equation reduces to

$$
s^{2}=\Sigma d_{i}^{2} / 2 n
$$

The estimate should be obtained from measurements made under conditions like those used during routine use of the measurement process to avoid omission of sources of error. For example, if it is the normal practice to use several instruments or several operators for the process measurements, the estimates calculated from replications are applicable to all measurements only if the replicate data involve all of these sources of error, unless tests have shown that between-instrument and between-operator effects are negligible. 


\subsection{COMBINING ERRORS AND CALCULATING LEID}

The limits of error of shipments, receipts and ID's, which are sums or linear combinations of many individual values, are of primary interest in SNM accounting. Calculation of the limits of error of these quantities requires consideration of both random error standard deviations and the standard deviations of the calibrations and bias estimates. A system of statistical procedures for estimating such errors and calculating LEID is explained and illustrated with practical examples by Jaech. ${ }^{(49)}$

\subsection{PLANNING MEASUREMENT CONTROL DATA COLLECTION}

Establishing a data collection schedule for monitoring samplings, measurements, and calibrations requires a knowledge of: 1) the measurement methods being used and their expected accuracies and precisions, 2) the processing schedules and material flows, and 3) any planned changes in either processes or measurement methods. When individual measurement errors are combined to obtain LEID, the statistician performing the calculations usually knows how much data are available for each error source estimate, how current the data are, and what trends in the various sources of error have occurred. In addition, the relative contribution of the various sources of error in the overall material balance can be assessed. From this information, the statistician can identify measurement deficiencies and plan future calibrations, measurements of standards, replicate samplings and analyses, and other tests of measurement quality in a manner that ensures adequate control data but avoids the acquisition of excessive information at unnecessary expense.

\subsection{STATISTICAL DESIGN OF EXPERIMENTS}

Special studies or experiments often are necessary to identify and estimate sources of error and to develop bias-free methods for mixing, sampling, or analysis. Such studies are usually more efficient and thorough if they are designed to facilitate statistical analysis of the data. An example of an experimental approach for determining the magnitude of uncertainty due to sampling bias is shown in Reference 15. Other experimental designs useful in measurement control are described in References 26 and 27. 


\subsection{NUMBER OF DEGREES OF FREEDOM REQUIRED}

Confidence limits for an estimated value depend on the number of degrees of freedom (usually one less than the number of measurements in the case of simple replicate measurements) associated with the calculated standard deviation. Tests of the statistical significance of an apparent bias or an apparent change of standard deviation are related to the confidence interval. Determining how many degrees of freedom are needed for each measurement error estimate is a statistical analysis task.

The number of replicate sets and their spacing over time needed to adequately monitor random error during a given time period is largely a matter of technical judgment. The same is true when measurement accuracy is monitored by analyzing standards to obtain a satisfactory estimate of a bias correction or of the standard deviation of the bias estimate. In each case the number of measurements is contingent on the degree of confidence in the error values needed to obtain a precise estimate of LEID. (Discussions of confidence interval determinations and hypothesis testing are found in most statistics books.) $(4,26,27)$ The confidence interval for an estimate of variance, $s^{2}$, as a function of the number of degrees of freedom (d.f.) in the estimate can be estimated from a table of the $\chi^{2}$ function where:

$$
\chi^{2}=\frac{s^{2}}{\sigma^{2}} \cdot(\text { d.f. })
$$

Such an analysis shows that appreciable gains in the limits for $\mathrm{s}^{2}$ are achieved by increasing the degrees of freedom up to about 15 . As a general guide, therefore, the minimum number in sets of duplicate measurements for making a determination of the estimated random error standard deviation for a measurement process should be about 15 .

The basic formula for estimating the standard deviation of the calculated mean of a set of measurements of a reference standard is:

$$
s_{\bar{x}}=\sqrt{\frac{s_{x}^{2}}{n}}
$$


where

$s_{x}^{2}=$ the estimate of the variance of the measurement process

$\mathrm{n}=$ the number of measurements obtained.

An analysis of the limits of error of $\bar{x}$, e.g., $25_{\bar{x}}$, as a function of $n$ shows that beyond 10 to 15 values very little gain is made in reducing $s_{\bar{x}}$. However, when determining a bias correction factor, an $n$ of at least 10 shourd be obtained. Therefore, if an independent bias estimate is made weekly, the reference standard should be measured approximately twice daily.

\subsection{REJECTION OF OUTLIER DATA}

A common statistical problem in measurements is dealing with outlier observations. An outlier may be merely an extreme manifestation of the ordinary variability in the data, in which case the value should be retained. on the other hand, the outlier may have been caused by an identifjable physical deviation in a procedure, by a miscalculation, or by an error in data recording or transcribing. The first step in dealing with an outlier is to look for a physical cause; if one is established, the outlier should be rejected. If no physical cause is found or if there is any doubt about the cause, a statistical test should be applied.

For a single outlying observation, one test is to determine whether the difference between the outljer and the mean of all of the data (including the outlying value) is within acceptable linits about the mean, based on an estimate of the variance of the current data. Acceptable procedures for setting the limits for rejecting an outlier have been published by ASTM, (50) F. E. Grubbs, (51) and G. L. Tietjen. (52) A Regulatory Guide ${ }^{(53)}$ has also been published on this subject.

\subsection{EVALUATING DATA TRENDS}

The sequences of results from the analysis of standards, ranges of replicate measurements, or estimates of error should be monitored to detect any shifts in error levels. Control charts are convenient devices for observation of such sequential data. When a shift or trend is suspected, a physical 
explanation for the apparent shift is sought. If there is no physical explanation, statistical tests should be applied to the data. Hypothesis testing is a frequently used method for detecting a significant change in the mean value of a measurement process (see Chapter 8 in Reference 4). Alternatively, one of the tests for nonrandomness suggested by Jaech can be used (see Chapter 2 in Reference 4). Also such data are usually tested for normality. (54)

If the variance of a set of data appears to differ from the variance of previous sets, the estimated variances can be tested by the F-test or Bartlett's test. (15) For example, if it is desired to combine a variance estimate from a previous material balance period with a variance estimate for the current material balance period, a statistical test should be used to show whether or not the variances of the current data and of the older data are significantly different. In a similar situation tests of the mean values from the analys is of standards are needed to determine whether calibrations of instruments or standards have changed significantly. (See statistical tests for differences between mean values in Chapter 8 of Reference 4.) If there have been no trends over time, the advantages of combining calibration data from more than one material balance period is that more data may help to establish a more precise calibration. However, such data should not be combined without statistical justification.

\subsection{SETTING CONTROL LIMITS}

Control charting procedures help monitor measurement quality by providing operators, analysts, and measurement control personnel with a practical and rational means of detecting loss of statistical control. (55) The use of control charts is similar to hypothesis testing. A control chart is usually a sequential plot of statistics with preestablished horizontal lines indicating the expected value along with upper and lower control limits. The control limits are based on historical estimates of variability for the measurement process while it is in statistical control with $2 \mathrm{~s}$ and $3 \mathrm{~s}$ limits being the most common. Examples of control charts are: 
- mean or $\bar{x}$ charts

- range or $R$ charts

- standard deviation or s charts

- fraction defective or $p$ charts.

Rather than plotting individual observations, the mean or average of subgroups of data is very often used to reduce the effect of random errors and to increase the sensitivity for detecting bias. The use of cumulative sum charts should also be considered for monitoring the cumulative effects of small losses or biases such as cumulative ID. ${ }^{(56-59)}$ 


\subsection{PROGRAM CONTROL AND ADMINISTRATION}

A measurement control program should provide for the administration of a variety of control measures relating to measurement processes and equipment, personnel competence, measurement methods, information flow and records, and program reviews and audits. Recommendations for establishing and maintaining such controls are presented in this section.

\subsection{ADMINISTRATION OF A MEASUREMENT CONTROL PROGRAM}

Administration of a measurement control program is similar in many ways to administration of safety, nuclear materials control and accounting, and quality assurance programs. Such administrators must maintain effective liaison with several other organizations since the successful exercise of their responsibilities is affected by decisions and activities of many people. The staff of a measurement control program has important interactions with the personnel responsible for production planning, material processing, nuclear material accounting, product quality control, and analytical services. Therefore, a formal plan of organization is necessary to clearly define the scope of responsibilities and authorities involved in the various activities that can affect the quality of SNM measurements. Some of the key activities involved are selection, review and approval of measurement methods; acquisition, preparation and care of reference standards; calibration services; statistical design and analysis; personnel training and qualffication and records.

The primary responsibility for planning, developing, coordinating and administering the program should be assigned to an individual who holds a position at an organizational level that permits independent and objective action. He should have the full support of top levels of management. His authority should be sufficient to obtain all of the information needed to monitor and evaluate measurement quality, to prescribe corrective actions when measurement quality fails to meet management goals, and to ascertain whether the actions have been taken. The administrator should not have 
responsibilities of an operational nature that may result in conflicting goals. This type of management precludes making the important measurement control functions into subsidiary assignments or splitting responsibilities among several groups in a way that might weaken authority and hamper coordination.

Under the direction of this administrator will be a staff with the technical skills needed to plan and schedule collection of program data, to assemble and apply statistical methods in the analys is of the data, and to provide conclusions and recommendations to appropriate line management. Some of the required skills may need to be obtained through other groups but centralized measurement control responsibility and authority should be the accepted mode of operation.

Effective working relationships and communication channels should be established among individuals and groups involved in measurement control, nuclear materials accounting, analytical services, process engineering, and production operations. In addition, the measurement control staff should have complete and timely access to flow sheets and operating plans (including the expected compositions of inventories and of the process materials flowing into and out of each material balance area), to plans for process changes, and to sampling and analysis schedules as well as all measurement monitoring data.

\subsection{PROGRAM PLAN}

The measurement control program plan should be documented and formally approved by management. The program plan should contain: 1) program policy directives, 2) organizational charts and directives, 3) descriptions of duties, responsibilities, and authorities of personne] performing measurement control functions, 4) approved program instructions and procedures, and 5) instructions for the use of approved forms and formats for records and reports. The description of the program should identify the measurements and other activities that must be monitored in order to evaluate and control measurement quality and describe the calibration and standardization procedures and schedules, the data control and statistical evaluation procedures and the additional program control procedures that are used to ensure that the 
measurement facilities, equipment and instruments, procedures, personnel, and information systems will be continually monitored for effectiveness in furthering the measurement control program purposes.

\subsection{REVIEW OF DESIGNS, INSTALLATIONS, AND TESTS OF FACILITIES AND EQUIPMENT}

The quality of materials accounting measurements can be limited by features of facility design. For example, if the design of a facility does not provide sufficient accessibility to in-plant measurement equipment, recalibration may not be feasible. Also, failure to provide a proper environment may expose measurement equipment to corrosive vapors, excessive temperatures, or undesirable vibrations. Unless sufficiently rigid design specifications are set, measurement equipment may lack the needed sensitivity or reproducibility for the measurement task. Consideration of measurement system requirements during design, construction, or modification of nuclear process facilities and during the preparation of design or purchase specifications for the measurement equipment can reduce subsequent measurement control problems. Design reviews for measurement control would serve a purpose similar to that served by reviews for industrial and nuclear safety. Some guidelines for measurement control design reviews are available in References $12,16,24,32$ and 60.

The design, specifications, and planned usage of all facilities and equipment whose functioning may have an impact on measurement quality should be reviewed prior to the final design or purchase commitments in order to permit timely intervention and changes. Those who perform these reviews should understand the measurement control program and also the measurement technology and purposes and functions of the facilities or equipment under consideration. They should have sufficient authority to withhold approval of an item until all questions of measurement control are resolved. At a minimum, the reviews should ensure that: 
- sufficient consideration is given to design and installation features that would provide for acceptable measurement and sampling capabilities in the facility

- access and capabilities are provided to facilitate calibrations, tests, and maintenance of measurement and sampling equipment and instruments after startup

- all criteria and conditions necessary for achieving acceptable measurement quality are specified in purchase orders, design drawings, and instructions

- all special services and environmental conditions needed for successful operation of the measurement systems are provided, including any requirements for stabilized power sources and protection of instruments from humidity extremes, excessive temperature, vibration, and corrosive vapors. Any exceptions, deviations, and design changes should also be controlled by the review and approval procedure to ensure that measurement quality is not adversely affected. Before use, new or modified measurement and sampling facilities and equipment should also be tested for operability and compliance with specifications. The preoperational test and calibration plans and their results should be reviewed by measurement control program personnel to ensure that the facility or equipment actualiy meets the measurement requirements.

When instruments, equipment, and measurement systems are calibrated, the data should be reviewed before application to ensure that: 1) the calibration range is adequate, 2) the equipment meets performance criteria related to such parameters as range, sensitivity, drift rate, and stability, and 3) the calibration and test data are adequate to establish acceptable operating procedures and to establish a sufficiently small standard deviation for the calibration curve.

Complete records of designs, specifications, fabrication, and test data should be retained at least 5 years (see Section 70.57 of Reference 1) to permit retracing the performance history of facilities and equipment that 
affect measurement quality. If a set of calibration data is applicable to current measurements beyond 5 years, the calibration records should be retained for at least a year beyond the time when the calibrations are no longer applicable to current measurements.

\subsection{REVIEW OF MEASUREMENT METHODS}

The choice of a measurement method often requires a compromise among such desirable characteristics as accuracy, precision, range of application, freedom from interferences, speed, economy, and availability. A systematic approach to method selection is based on matching method characteristics to preestablished and prioritized requirements. Ultimately, the way in which priorities are assigned to the method characteristics determines the method chosen, which in turn affects measurement quality.

Formal review and approval procedures should be established and maintained for in-plant measurement, sampling, NDA and laboratory analytical methods. The reviews should be concerned primarily with the impact that the proposed method or modification to an existing method would have on the error of the measurement and on the LEID. The approval should be based on predefined minimum requirements of the measurement. The requirements should be derived and justified by statistical analysis of material balance data and other information developed by the measurement control program.

The following purposes are served by establishing a formal procedure for review and approval of the measurement methods:

- the needs of SNM control and accounting as we11 as process and product quality control are adequately considered. (Many of the measurement methods in nuclear material processing plants serve more than one purpose.)

- planned changes in procedures are reviewed by the personnel responsible for measurement quality control before the changes are made

- application of the measurement procedures will be more consistent and measurement control data more stable and predictable. 


\subsection{TRAINING AND QUALIFYING PERSONNEL}

The quality of measurements used in nuclear materials control and accounting can be affected by the knowledge, skill, and care of the persons who perform the measurements. It is important that sampling, bulk measurements, laboratory and nondestructive assay, and equipment calibrations be carried out by individuals who are adequately qualified for these jobs. Procedures for selecting, training, and evaluating such persons for job certification should be planned and carried out to ensure that performance is consistent, uniform and of acceptable quality. When an evaluation indicates that a person is not performing a measurement task adequately, the situation can be corrected by either retraining or reassigning the person.

Initiation of a personnel selection, training and qualifying program should involve the following steps:

- select the positions to be subject to the qualification program

- prepare descriptions of those positions, as well as a breakdown of the specific knowledge and skills prerequisite for the positions

- translate the job requirements into a qualification program that includes orientation, training, and evaluation.

The position qualifications and the evaluation procedures to be used should be fully described in writing. Evaluation procedures should state the testing method and the scores and other performance goals to be required of candidates for qualification in each position category. By establishing these things in advance, an effective training plan can be developed for each job and the qualification of personnel is likely to be objective.

Training should be closely related to both the specific job requirements and the individual's training needs. Direct on-the-job instruction by a supervisor or another skilled employee may be an important component of the training program. A preassessment of each candidate's capabilities can identify the kind of training needed so that the training plan and period of time can be adjusted to individaul needs. 
Evaluation procedures should be designed to provide assurance that an individual knows and understands the measurement process and is capable of performing it with acceptable accuracy and precision. For most measurement jobs, the evaluation should be based primarily on a demonstration by the individual of his ability to perform the required job tasks; for example, the evaluation test of a chemical analyst should include an analysis by the candidate of a series of reference materials similar to the usual process samples and the precision and freedom from bias of the results obtained should meet pre-established criteria for qualification. These criteria should ordinarily be based on the expected levels of performance for maintaining qualification by all personnel holding that position. The specific qualifications criteria and evaluation procedures should be chosen by those responsible for the job performance and should be approved by the director of the measurement control program. An analyst qualification program of this kind has been described by Huff and Tingey. (61)

Individual performance should be reevaluated periodically, for example, annually, to ensure that each person's capability and performance continue to meet the job requirements. Any indication of substandard job performance should be followed by corrective steps such as retraining or reassignment. Records of the certification status of each person should be maintained in accordance with the requirements of 10 CFR $70.57(b)(12)$.

\subsection{RECORDS CONTROL}

Records associated with a measurement control program are normally retained to furnish documentary evidence of measurement quality and compliance with measurement control program procedures. They also permit tracing of measurement control data to original data sources.

The records should include all data, information, reports and documents generated by the measurement control program and summaries of the measurement control data utilized in the limit of error calculations for each material balance period. The system of measurement control program records should facilitate tracing of any reported result to the original measurement control 
information, including pertinent calibration data. The records should be organized for timely retrieval of program information and retained for at least five years. (a)

For complete traceability of measurement control data, records should normally include the original data or formal documentation of:

- equipment calibrations

- measurements of standards and replicate measurements of process material for determining the errors associated with the measurement and evaluations of the data

- preparations and calibrations of standards

- bias corrections

- statistical analyses of measurement data

- the test results for the approved bulk material mixing and sampling procedures

- designs, specifications, and preoperational tests of measurement equipment and methods

- approvals of measurement methods and standards

- records of training and qualifying persons performing measurement tasks covered by the program

- records of audits, reviews, evaluations, and special studies. Records control should be planned and formalized to assure complete and uniform record keeping practices and assignment of custodianship responsibilities for each type of record. In addition, the design and required distribution of forms should be standardized.

(a) See Section 70.57 of Reference 1 . 
Certain historical information useful for tracing of measurement control data may be needed for a longer period and management should take this into account when establishing the records retention policy. Examples of such historical information are:

- equipment and instrument design and test information, including preoperational tests

- equipment and instrument calibration data and details of the calibration procedures

- mixing and sampling test information

- tolerances and other certification information on standards.

\subsection{PROGRAM AUDITS (a)}

Management should audit the measurement control program approximately yearly. Periodic program audits are a means of assuring that program policies and procedures do not become obsolete or irrelevant. Such audits provide for a periodic check on compliance with the program plan and a reconsideration of the adequacy and effectiveness of the program design. In addition, valuable new perspectives and new ideas are usually introduced as a result of the normal turnover of personnel conducting audits. A major emphas is in the audits should be on the effectiveness of the program, i.e., its degree of success in meeting program goals and objectives. Since human activities are subject to errors, periodic audits are necessary to ensure that errors and deviations from the approved procedures as well as obsolescence have not invalidated the measurement control system.

The responsibility for conducting an audit should be assigned to a person with no direct responsiblity for any measurement control program functions. The auditor should have administrative and auditing experience and sufficient knowledge of quality control systems and measurement technology to ensure competent and objective judgments of the effectiveness of the program.

(a) The term audit is used in this report to identify the functions of both reviews and audits as these functions are defined in 10 CFR 70.57 (b)(2). 
A team may be utilized for this purpose. The measurement control program audits may be done in combination with audits of the special nuclear material control and accounting system.

The auditor should prepare an audit plan and a set of key questions in advance. He should study the previous audit reports in this planning stage and plan a follow-up on the recommendations made by previous auditors. The plan should then be discussed with the measurement control program director and arrangements made to conduct the audit.

The first step in the audit is to independentily verify that the measurement control program complies with NRC regulations and the license conditions. Compliance tests will apply to both the written program plan and its implementation. A thorough examination of all aspects of the program will usually require evaluations of compliance in each of the following areas:

- program management and organization

- implementation of policies and procedures

- measurement control procedures

- control of measurement method selection and applications

- preoperational evaluation of the acceptability of sampling and measurement equipment and their installations

- training and qualifying program for measurement personnel

- calibration and reference standards program

- data collection and analysis

- calibration and bias test frequencies

- random error variance monitoring program

- special tests and comparative analyses

- statistical data analysis procedures

- records and reports.

The auditor's evaluation of the measurement control program design and implementation from the standpoint of relevancy and effectiveness will 
inevitably be subjective by comparison with auditing for compliance. It must be determined how each of the elements of the program contributes to meeting the objectives and purposes of measurement control for nuclear materials accounting rather than the specific requirements of regulations, directives and license requirements. This report combines an explanation of objectives and purposes with the descriptions of recommended measurement control program design features. As such, it can be a guide to program evaluation. In addition, the auditor should examine the objective indicators of the state of nuclear materials control and accounting. Some of the indicators that are most directly affected by a measurement control program are:

- the magnitude of the historical IDs and their randomness

- comparisons of the standard deviations of IDs derived by propagation of measurement error data and those calculated from historical IDs

- comparisons between the measurement standard deviations being achieved and the current state-of-the-art information for similar applications

- comparisons of shipper and receiver data.

The auditor should issue a report to management which describes his procedures, results, and recommendations. When the audit discloses discrepancies between performance and measurement control program requirements, management should promptly initiate follow-up action to correct any deficiencies. The program director should review the discrepancies, make recommendations for such action, and follow up on the actions taken. 


\section{REFERENCES}

1. Code of Federal Regulations, Title 10. "Energy", Chapter 1, Part 70, U.S. Government Printing office, Washington, OC, January 1978.

2. Semi-Annual Report on Strategic Special Nuclear Material Inventory Differences. DOE/DR-0001-1, U.S. Department of Energy, Office of Safeguards and Security, Washington, DC, January 1978.

3. Code of Federal Regulations, Title 10. Part 70, Section 70.51, U.S. Government Printing Office, Washington, DC.

4. J. L. Jaech, Statistical Methods in Nuclear Material Control, USAEC Report TID-26298, U.S. Atomic Energy Commission, 1973.

5. Statistical Terminology and Notation for Special Nuclear Materials Control and Accountability. Regulatory Guide 5.3, January 1973, and ANSI Standard N15.5-1972, American Nationa1 Standards Institute, 1430 Broadway, New York, NY, 1972.

6. C. Eisenhart, "Realistic Evaluation of Precision and Accuracy of Instrument Calibration Systems." in Precision Measurement and Calibration, $1: 21-47$, NBS SP-300, H. H. Ku (ed.), U.S. Government Printing Office, Washington, DC, 1969.

7. J. L. Jaech, "Some Thoughts on Random Errors, Systematic Errors, and Biases." Nucl. Mater. Manage., $\underline{3}(4): 37-39$, Winter 1975.

8. J. L. Jaech, "Some Thoughts on Bias Corrections." Nucl. Mater. Manage., $4(2): 40-44$, Surmer 1975 .

9. R. H. Moore, "Some Thoughts on 'Some Thoughts on Random Errors, Systematic Errors, and Biases' by John L. Jaech." Nucl. Mater. Manage., $\underline{4}(1): 44-46$, Spring 1975 .

10. S. C. Suda, "Some Thoughts on Constant and Variable Components of Systematic Error." Nucl. Mater. Manage., 4(1):41-43, Spring 1975.

11. 0. L. Davies, (ed.), The Design and Analysis of Industrial Experiments. Chapter 2, Hafner Pub7ishing Co., New York, NY, 1967.

12. Volume Calibration Techniques for Nuclear Materials Control. ANSI Standard N15.19, American National Standards Institute, 1430 Broadway, New York, NY, 1975.

13. Conduct of Nuclear Material Physical Inventories. Regulatory Guide 5.13, U.S. Nuclear Regulatory Commission, Washington, OC, 1973. 
14. S. C. Suda and D. F. Shepard, Effects of Measurement Errors on Linear Caljbration Equations. BNL-50432, NationaT Technical Information Service, Springfield, VA, 1976 .

15. J. L. Jaech, Statistical Methods in Nuclear Material Control. Chapter 3, USAEC Report TID-26298, U.S. Atomic Energy Commission, 1973.

16. Mass Calibration Techniques for Nuclear Material Control. ANSI Standard N15.18, American National Standards Institute, 1430 Broadway, New York, NY, 1975.

17. "Standard Methods for Testing Single Arm Balances." ASTM Standard E-379-68, Annual Book of ASTM Standards, Part 41, American Society for Testing and Materials, 1916 Race Street, Philadelphia, PA, 1978.

18. "Probability Sampling of Materials." ASTM Standard E-105-58, Annual Book of ASTM Standards, Part 41, American Society for Testing and Materials, 1916 Race Street, PhiTadelphia, PA, 1978.

19. "Sampling Industrial Chemicals." ASTM Standard E-300-73, Annual Book of Standards, Part 30, Anerican Society for Testing and Materiais, 1916 Race Street, Philadelphia, PA, 1978.

20. "Choice of Sample Size to Estimate the Average Quality of a Lot or Process." ASTM Standard E-122-72, Annual Book of ASTM Standards, Part 41, American Society for Testing and Materials, 1916 Race Street, Philadelphia, PA, 1978.

21. C. A. Bicking, "The Sampling of Bulk Materials." Materials Research and Standards, $\underline{7}(3): 95-116$, March 1967.

22. H. Harnby, "The Statistical Analysis of Particulate Mixtures, Part 1. The Sampling of Mixtures and the Resultant Precision of Estimates." Powder Tech., 5:81-86, 1972.

23. C. L. Grant and P. A. Pelton, "Role of Homogeneity in Powder Sampling." ASTM Special Technical Publication 540, American Society for Testing and Materials, 1916 Race Street, Philadelphia, PA, 1973.

24. R. J. Brouns, F. P. Roberts and U. L. Upson, Considerations for Sampling Nuclear Materials for SNM Accounting Measurements. NUREG/CR-0087 (PNL-2592), National Technical Information Service, Springfield, VA, May 1978.

25. J. C. Williams and M. I. Kahn, "The Mixing and Segregation of Particulate Solids of Different Particle Size." The Chemical Engineer. 269:19-25, 1973.

26. C. A. Bennett and N. L. Franklin, "The Oesign of Experiments." Chapter 8, 478-627, in Statistical Analysis in Cherristry and the Chemical Industry, John Wiley and Sons, New York, 1954. 
27. F. H. Tingey, "Design of Experiments in Analytical Chemistry Investigation." Treatise on Ana Tytical Chemistry, 10(1):6406-6493, I. M. Kolthoff and P. J. Elving, (eds.), John Wiley and Sons, New York, 1972.

28. C. J. Rodden, (ed.), Selected Measurement Methods for Plutonium and Uranium in the Nuclear Fuel Cycle. USAEC Report TID-7029, National Technical Information Service, Springfield, VA, 1972.

29. F. B. Stephens, R. G. Gutmacher, et al., Methods for the Accountability of Plutonium Dioxide. WASH-1335, 1974; Methods for the Accountability of Uranium Dioxide, NUREG-75/010, 1975; and Methods for the Accountability of Mixed Oxide, NUREG-0256, 1977. National Technical Information Service, Springfield, VA.

30. E. L. Garner, L. A. Machlin and W. R. Shields, Uranium Isotopic Standard Reference Materials, NBS Special Publication 260-27, U.S. Government Printing office, Washington, DC, 1971.

31. W. R. Shields, (ed.) Analytical Mass Spectrometry Section: Instrumentation and Procedures for Isotopic Analysis. NBS Technical Note 277, Superintendent of Documents, U.S. Government Printing Office, Washington, DC, 1966.

32. Guide to Calibrating Nondestructive Assay Systems. ANSI N15.20, American National Standards Institute, 1430 Broadway, New York, NY, 1975.

33. Nondestructive Assay of Special Nuclear Material Contained in Scrap and Waste. Regulatory Guide 5.11, U.S. Nuclear Regulatory Commission, Washington, DC, October 1973.

34. T. E. Shea, "Reduction, Control and Estimation of Nondestructive Assay Errors." Proceedings of the 15th Annual Meeting, Institute of Nuclear Materials Management, Atlanta, GA, June 1974.

35. J. E. Glancy, "Traceability of Nondestructive Assay to the Nationa] Measurement System." Proceedings of the 15th Annual Meeting, Institute of Nuclear Materials Management, Atlanta, $\overrightarrow{G A}$, June $19 \overline{74}$.

36. Qualification, Calibration, and Error Estimation Methods for Nondestructive Assay. Regulatory Guide 5.53, U.S. Nuclear Regulatory Commission, Washington, DC, 1975.

37. R. H. Augustson, Dymac Demonstration Program, Phase I Experience. LA-7126-MS, Los Alamos Scientific Laboratory, Los Alamos, NM, (Appendix D), 1978.

38. Calibration and Test Services of the National Bureau of Standards. NBS Special Publication 250, Superintendent of Documents, U.S. Government Printing Office, Washington, DC, 1970. 
39. T. W. Lashof and L. B. Macurdy, Precision Laboratory Standards of Mass and Laboratory Weights. NBS Circular 547, Section 1, Superintendent of Documents, U.S. Government Printing Office, Washington, DC, 1954.

40. Method for Liquid Calibration of Tanks. ASTM Standard D-1406-65, American Society for Testing and Materials, 1916 Race Street, Philadelphia, PA, 1975.

41. J. C. Hughes, Testing of Glass Volumetric Apparatus. NBS Circular 602, Superintendent of Documents, U.S. Government Printing Office, Washington, DC, 1959.

42. Analytical Procedures for Accountability of Uranium Tetrafluoride. ANSI N15.6-1972; and Analytical Procedures for Accountability of Uranium Hexafluoride. ANSI N15.7-1972, American National Standards Institute, 1430 Broadway, New York, NY.

43. L. A. Ku17, Catalogue of Nuclear Material Safeguards Instruments. USAEC Report, BNL-17165, 1972 .

44. Considerations for Establishing Traceability of Special Nuclear Material Accounting Measurements, Regulatory Guide 5.58, U.S. Nuclear Regulatory Commission, Washington, DC, 1979.

45. Catalog of Standard Reference Materials. NBS Special Publication 260, Superintendent of Documents, U.S. Government Printing Office, Washington, DC, 1973.

46. H. T. Yolken and F. E. Jones, Measurements and Standards for Nuclear Materials Safeguards. NUREG/CR-0533, National Technical Information Service, Springfield, VA, 1978.

47. G. C. Swanson, S. F. Marsh, J. E. Rein, G. L. Tietjen, R. K. Zeigler and G. R. Waterbury, Preparation of Working Calibration and Test

Materials - Plutonium Nitrate Solution. NUREG-D118 (LA-NUREG-6348), National Technical Information Service, Springfield, VA, 1976.

48. S. S. Yamamura, F. W. Spraktes, J. M. Baldwin, R. L. Hand, R. P. Lash, and J. P. Clark. Preparation of Working Calibration and Test Materials Uranium Nitrate Solution, NUREG-0253, National Technical Information Service, Springfield, VA, 1977.

49. J. L. Jaech, Statistical Methods in Nuclear Material Control. Chapter 4, Section 4.1 and Chapter 6, Section 6.1, USAEC Report TID-2628, 1973.

50. "Recommended Practice for Dealing with Outlying Observations". ASTM Standard E-178-75, Annual Book of ASTM Standards, Part 41, American Society for Testing Materials, 1976 Race Street, Philadelphia, PA, 1978. 
51. F. E. Grubbs, "Procedures for Detecting Outlying Observations in Samples." Technometrics, 1] (1):1-21, 1969 .

52. G. L. Tietjen and R. H. Moore, "Some Grubbs-Type Statistics for the Detection of Several Outliers." Technometrics, 14:583, 1972.

53. Recommended Practices for Dealing with Outlying Observations. Regulatory Guide 5.36, U.S. Nuclear ReguTatory Commission, Washington DC, 1974.

54. Assessment of the Assumption of Normality. ANSI Standard N75.15, American National Standards Institute, 1430 Broadway, New York, NY, 1974.

55. Control Chart Method of Controlling Quality During Production. American Standards Association, Standard 21.3-1958, American National Standards Institute, 1430 Broadway, New York, NY.

56. J. L. Jaech, Statistical Methods in Nuclear Material Control. Chapter 2, Section 2.8.3, USAEC Report TID-26298, 1973.

57. N. L. Johnson and F. C. Leone, "Cumulative Sum Control Charts, Part I." Industrial Quality Control, 18(12):15-21, June 1962.

58. J. L. Jaech, "On Forming Linear Combinations of Accounting Data to Detect Constant Sma17 Losses." Nuclear Materials Management, 4(4):37-42, Winter 1977-78.

59. W. D. Evans, "When and How to Use Cu-Sum Charts." Technometrics, 5(1):1-22, February 1963 .

60. Design Considerations, Systems for Measuring the Mass of Liquids. Regulatory Guide 5.48, Nuclear Regulatory Commission, Washington, DC, 1975.

6T. G. A. Huff and F. H. Tingey, "Statistically Designed Training Program for an Analytical Control Laboratory." Ana]. Chem., 29(8):19A-22A, August 1957. 
A MEASUREMENT CONTROL PROGRAM FOR NUCLEAR MATERIAL ACCOUNTING

$\because$ AUTHORIS\}

R.J. Brouns, F.P. Roberts, J.A. Merri11, and W.B. Brown

6. PERFORMING OAGANIZATION NAME AND MAILING ADDRESS (inciude $Z_{0} \rho$ COde)

Energy Systeris

Pacific Northwest Laboratories

P.0. Box 999

Richland, WA 99352

3. AECIPIENT'S ACCESSIONN NO.

5. DATE REPORT COMPLETED SANTH TEAA September

2. SPONSSORING ORGANIZATION NAME AND MAILING ADORESS (Include $Z$ ip COde) Office of Standards Development

U.S. Nuclear Requlatory Commission

klashinaton, $n C 20555$

\begin{tabular}{l|l} 
DATE REPORT ISSUED \\
\hline MONTH
\end{tabular}

6. (Leave hlank)

IUNE

8. (Leave btank)

10. PROJECTITASK/WORK UNIT NO

11. CONTRACT NO.

B 20149

13. TYPE OF REPOAT

Technical Report

PEAIOD COVERED (InCfusive datES)

Nov., 1973 - Sept., 1979

15. SUPPLEMENTARY NOTES

14. (Leave blank)

16. ASSTRACT ROO words or less)

A most important element of a program by which management can monitor and contro] measurement quality. The scope of the publication shows that a measurement control program for nuclear materials accounting monitors and controls the quality of the measurements of special nuclear material that are involved in material balances. The quality is monitored by collecting data from which the current precision and accuracy of measurements can be evaluated. The quality is controlled by evaluations, reviews, and other administrative measures for control of selection or design of facilities, equipment and measurement methods and the training and qualification of personne? who perform SNM measurements.

17. KEY WORDS AND DOCUMENT ANALYSIS

Measurement control Nondestructive Assay

Calibration

Heighina

Sampling

Isotopic Analys is

17b. IDENTIFIERS/OPEN-EN DED TERMS

PD, Random Error, Bias, Nondestructive Assay, Mea surement Control

18. AVAILABIEITY STATEMENT

Unclass ified 17a. DESCRIPTORS

Tank Calibration

Random Error

Estimating Bias

\begin{tabular}{|c|c|}
\hline $\begin{array}{l}\text { 19. SE CUAITY CLASS (This renort) } \\
\text { UnlLimi }\end{array}$ & 21. NO. OF PAGES \\
\hline 20. SECURITY CLASS (This nate) & $\begin{array}{l}\text { 22. PHICE } \\
\mathrm{s}\end{array}$ \\
\hline
\end{tabular}

